\title{
Pushing Typists Back on the Learning Curve: Contributions of Multiple Linguistic Units in the Acquisition of Typing Skill
}

\author{
Motonori Yamaguchi \\ Edge Hill University and Vanderbilt University
}

\author{
Gordon D. Logan \\ Vanderbilt University
}

\begin{abstract}
The present study investigated the way people acquire and control skilled performance in the context of typewriting. Typing skill was degraded by changing the location of a key (target key) while retaining the locations of other keys to disable an association between the letter and the key. We conducted 4 experiments: Experiment 1 demonstrated that disabling a letter-key association affected not only the execution of the target keystroke but also the planning of other keystrokes for words involving the target key. In Experiments 2-4, typists practiced with a new target location and then transferred to a condition in which they typed the practiced words with the original key location (Experiment 2) or typed new words with the practiced key location (Experiments 3 and 4). Experiment 2 showed that the newly acquired letter-key association interfered with the execution of the original keystroke but not planning. Experiments 3 and 4 demonstrated that acquisition of the new letter-key association depended on multiple levels of linguistic units. Experiment 4 demonstrated that acquisition of the new association depended on sequences both before and after the target keystroke. We discuss implications of the results for 2 prominent approaches to modeling sequential behavior: hierarchical control and recurrent network models.
\end{abstract}

Keywords: skill acquisition, hierarchical control, recurrent network, typing, sequence production

Supplemental materials: http://dx.doi.org/10.1037/xlm0000026.supp

Typewriting is an important survival skill in modern society. Many of our interpersonal communications rely on computerized systems that require typing letters and digits. Thus, a large population of the modern society has had extensive training with typewriting. For instance, typical college students in the United States start typing at the age of 10 or younger, have taken a formal training in typewriting for a semester or two, and have experience in typing for more than 10 years, which qualifies them as domain experts in typing (see Logan \& Crump, 2011). The prevalence of typing skill provides an ideal ground for studying cognitive processes that support skilled performance. In the present study, we investigated the role of associations in acquisition of typing skill. Skilled typing is supported by three types of association: associations between words and letters, associations between letters and keys, and associations between keys and fingers (Yamaguchi \& Logan, 2014). The present study is concerned primarily with the associations between letters and keys. Following Gordon, Casab-

This article was published Online First June 16, 2014.

Motonori Yamaguchi, Department of Psychology, Edge Hill University, and Department of Psychology, Vanderbilt University; Gordon D. Logan, Department of Psychology, Vanderbilt University.

This research was supported by National Science Foundation Grants BCS 0957074 and BCS 1257272. We thank Matthew Crump, Alice Healy, and Luis Jimenez for valuable comments on drafts of this article.

Correspondence concerning this article should be addressed to Motonori Yamaguchi, Department of Psychology, Edge Hill University, Ormskirk, Lancashire, L39 4QP, United Kingdom. E-mail: yamagucm@ edgehill.ac.uk ona, and Soechting (1994) and Jordan (1995), we disabled one of the 26 letter-finger associations by replacing the position of a key (target key) and investigated how the replacement affected typing performance (Experiment 1) and how the new letter-key association is acquired through practice (Experiments 2-4). We focused particularly on the contributions of different linguistic units in the learning of typing skills. The results of the present study speak to the manner in which hierarchical control emerges in skilled performance.

\section{Hierarchical Control of Skilled Typewriting}

Language consists of a massive nested structure of different linguistic units: A text is composed of paragraphs, a paragraph is composed of sentences, a sentence is composed of words, and a word is composed of letters. Accordingly, control of typewriting behavior also involves hierarchically organized cognitive processes that address different linguistic units (Crump \& Logan, 2010a; Fendrick, 1937; Lashley, 1951; Logan \& Crump, 2011; Rumelhart \& Norman, 1982; Salthouse \& Saults, 1987; Shaffer, 1975; Yamaguchi, Crump, \& Logan, 2013). In skilled typewriting, appropriate levels of analysis are words and those below words. Evidence supporting this position is abundant (Fendrick, 1937; Shaffer \& Hardwick, 1968; West \& Sabban, 1982; Yamaguchi \& Logan, 2014). For instance, typing rate decreases when skilled typists type a text in which the orders of letters in words are scrambled, suggesting that words (or units below words) are important in skilled typewriting. However, typing rate is little influenced when skilled typists type a text in which the orders of words in sentences are scrambled, suggesting that sentences (and units 
above sentences) are not important in skilled typewriting. Therefore, theories of skilled typewriting are concerned with how typing behavior is controlled at the level of words and the levels below words (Crump \& Logan, 2010b; Logan \& Crump, 2011; Rumelhart \& Norman, 1982).

Logan and Crump (2011) proposed a two-loop theory of skilled typewriting, which assumes two nested control loops that divide labor between word- and letter-level processes (see Figure 1A). The word-level processes are controlled by an outer loop, which starts with encoding a word, submitting it to the lower level process, and monitoring errors in a typed word on the computer screen. The letter-level processes are controlled by an inner loop, which translates letters into finger movements and presses the corresponding keys. According to the two-loop theory, typing performance manifests the contributions of the two control loops in term of two latency measures, response time (RT) and interkeystroke interval (IKSI; also see Fendrich, Healy, \& Bourne, 1991). RT is measured by the interval between onset of a word and a completion of the first keystroke, which includes the duration of the outer loop (encoding a word and planning a series of keystrokes; see Logan, Miller, \& Strayer, 2011; Yamaguchi \& Logan, 2014) and the duration of one iteration of the inner loop (executing the first keystroke). IKSI is measured by the interval between two successive keystrokes, which reflects finishing time differences between two successive iterations of the inner loop (see Yamagu-

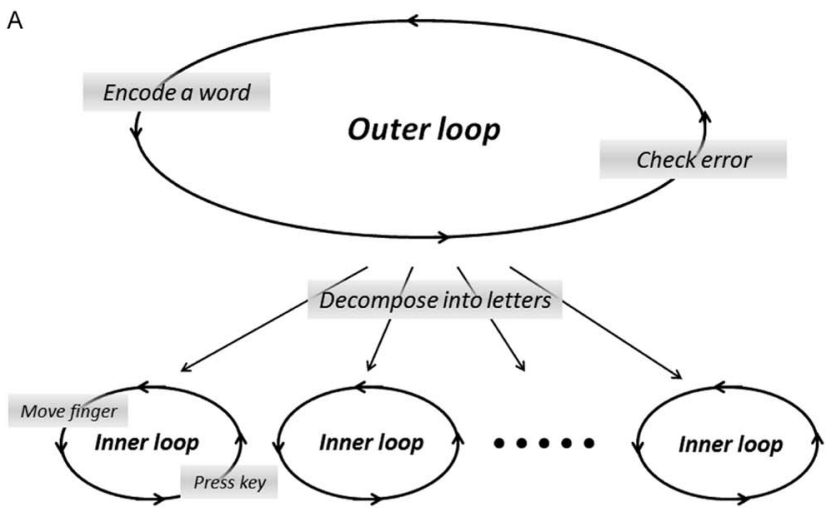

B

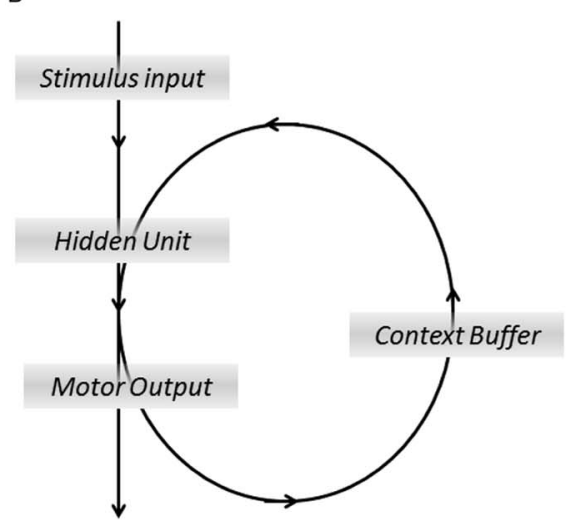

Figure 1. Schematic illustrations of (A) hierarchical control model (the two-loop theory) and (B) recurrent network model. chi, Logan, \& Li, 2013). Thus, the contributions of the two loops to skilled typing performance can be decomposed by looking at RT and IKSI.

\section{Three Associations Supporting Skilled Typewriting}

Typewriting is a highly trained skill that involves control of sequential actions. Studies of sequential behavior often rely on tasks in which subjects are trained with artificial materials such as an arbitrary series of symbols or positions on the display (e.g., Abrahamse, Ruitenberg, de Kleine, \& Verwey, 2013; Cohen, Ivry, \& Keele, 1990; Rosenbaum, Kenny, \& Derr, 1983; Stadler, 1992). Such tasks are suited to studying initial changes of performance in novel situations. However, it is difficult to train research subjects with these novel tasks for a long period of time that would be required for them to become "experts" of the tasks. In contrast, a majority of college students in modern society are already skilled typists who have had more than 10 years of experience in typing (Logan \& Crump, 2011). They provide a large pool of expert population for psychologists to study. Hence, typewriting is an ideal subject for studying skilled performance.

Also, an advantage of studying typewriting is that it enables researchers to compare skilled and unskilled performance within the same individuals, as opposed to between different individuals. This excludes possible confounding factors associated with developmental or socioeconomic differences between skilled and unskilled populations. Such intrapersonal comparisons can be done by altering familiar typing conditions, preventing typists from utilizing their typing skill, or pushing typists back on the learning curve (Yamaguchi \& Logan, 2014).

At each level of linguistic units, there exist unique associations that support skilled typewriting. Three major types of association include (a) associations between words and letters, (b) associations between letters and keys, and (c) associations between keys and fingers (see Yamaguchi \& Logan, 2014). The word-letter associations serve as an interface between the word-level and letter-level processes. This involves one-to-many mappings from words to letters, which gives rise to hierarchically structured control that allows parallel processing of multiple keystrokes (e.g., Logan \& Crump, 2011; Rumelhart \& Norman, 1982). The letter-key associations provide direct translation from letters to keys (Logan, 2003), so that skilled typists are able to type corresponding keys without being explicitly aware of where the keys are located on the keyboard (Liu, Crump, \& Logan, 2010; Snyder, Ashitaka, Shimada, Ulrich, \& Logan, 2014). The key-finger associations also support rapid keystrokes, so that skilled typists type the correct keys without being aware of which finger or the hand they use to type a specific key (Logan \& Crump, 2009; Snyder \& Logan, 2013). A few studies also suggest that there may be associations between letters and fingers (e.g., Beilock \& Holt, 2007; Kozlik \& Neumann, 2013; Kozlik, Neumann, \& Kunde, 2013; Rieger, 2004; Van den Bergh, Vrana, \& Eelen, 1990).

In a previous study (Yamaguchi \& Logan, 2014), we broke the associations between words and letters and between fingers and keys. We revealed the role of word-letter associations in chunking at stimulus encoding, short-term memory, and motor planning in skilled typewriting. We also found evidence indicating the role of key-finger associations in monitoring execution of individual keystrokes (also see Crump \& Logan, 2010c). In the present study, we 
examined the role of letter-key associations in the control of typing skill by moving one of the 26 letter keys to a novel position on the keyboard (Gordon et al., 1994; Jordan, 1995). We assessed how breaking a letter-key association affects the hierarchical components of skilled typewriting. We also investigated the acquisition of new letter-key associations, asking what linguistic units contribute to the acquisition process.

\section{What Is Involved in Acquisition of Typing Skill?}

Skilled typists differ from novices in their typing method. Novice typists hunt-and-peck: They start with encoding a single letter, finding a target key, and moving the finger to that key. The hunt-and-peck method imposes serial processing of individual keystrokes (Bryan \& Harter, 1899; Shaffer, 1986). Skilled typists touch-type: they start with encoding a word, translating it to multiple keystrokes, and executing them. The touch-typing method enables multiple keystrokes to be activated in parallel (Crump \& Logan, 2010b; Rumelhart \& Norman, 1982). Thus, the development of typing skill is characterized by a transition from the hunt-and-peck method to the touch-typing method, and the transition should be supported by acquisition of the three types of associations.

Several previous studies have investigated the development of sequential skills (Bryan \& Harter, 1899; Clegg, DiGirolamo, \& Keele, 1998; Jordan, 1995; Leonard \& Newman, 1964; Saffran, Newport, Aslin, Tunick, \& Barrueco, 1997; Stadler, 1992). Like the present study, Jordan (1995) examined the development of typing skill by switching the positions of a pair of keys and having his subjects undergo three days of training in typing single letters. Jordan's study provided evidence indicating the acquisition of specific letter-key associations and suggested that such associations are in part effector-specific (i.e., involving letter-finger associations). Another mechanism that is particularly important in the transition from novices to skilled typists is that of chunking (Bryan \& Harter, 1899; Leonard \& Newman, 1964).

Chunking is a central notion in hierarchical control models (Abrahamse et al., 2013; Salthouse \& Saults, 1987; Yamaguchi \& Logan, 2014). Chunking in typewriting depends on knowledge of words, but it should also depend on the probability of cooccurrences of events (i.e., contingency) because contingency promotes grouping of events in memory (Newell \& Rosenbloom, 1981). In skilled typewriting, chunking can occur at the perceptual level, the cognitive (memory) level, and the motor level (Yamaguchi \& Logan, 2014). Chunking provides a basis for hierarchical structure by scaling up units of processing from letters to words after repeated exposures to particular letter strings.

Contingencies between letters may also contribute to the transition from novice to skilled typists by strengthening associations between letters (or between keystrokes). The idea has been proposed as a model of sequential behaviors, known as a recurrent network model (Elman, 1990; Jordan, 1986). A recurrent network model is a connectionist idea in which activation of an event node depends on the input unit (stimulus) and the context buffer (previous output; see Figure 1B). The context buffer represents outputs of the model that precede the current stimulus, which serve as additional inputs to the hidden units that translate a stimulus input to a motor output. Thus, the context buffer provides an advantage for producing sequences of outputs that have occurred previously over sequences that have not occurred previously. The recurrent network model is capable of producing characteristic patterns of sequential actions that are predicted by a hierarchical model but without explicit representations of chunks (Elman, 1990). Hence, the model is viewed as an antithesis to the hierarchical control model (Botvinick \& Plaut, 2004), although these two models are not mutually exclusive.

A major difference between the hierarchical control model and the recurrent network model is the unit of processing: The hierarchical control model suggests that skilled typists process words, whereas the recurrent network model suggests that skilled typists process letters. Nevertheless, both hierarchical control models and recurrent network models are capable of predicting complex behaviors that involve a sequence of actions (Botvinick \& Plaut, 2004; Cooper \& Shallice, 2006; also see Rhodes, Bullock, Verwey, Averbeck, \& Page, 2004), and these two views of skill control have been difficult to distinguish empirically. A purpose of the present study is to make a step toward resolving this issue.

\section{The Present Study}

The main aim of the present study was to examine the role of letter-key associations in skilled typewriting. We broke one of the 26 letter-key associations in skilled typewriting by moving the location of a key (target key) and investigated how moving the key location affected typing performance and how the new letter-key association was acquired. We used a discrete typing task in which skilled typists typed a single word on each trial, and observed RT and IKSI to dissociate the influences of the key substitution on the outer loop and the inner loop (Logan \& Crump, 2011). Words consisted of 5 or 6 letters, and we varied the position of the target letter; the target could appear at the first, third, or fifth letter position in a word. We conducted four experiments.

The purpose of Experiment 1 was to establish how disabling a letter-key association affects skilled typing. Each typist performed the task with the target key moved to eight different key locations, varied between blocks (see Figure 2). Theoretical analyses of typewriting suggest that keystroke commands involve selecting hands, fingers, and rows (Grudin, 1983; Rumelhart \& Norman, 1982). Consequently, we chose these eight key locations to counterbalance the relations between the original location and the substituted locations (e.g., using different fingers, different hands, or different rows on the keyboard; note that this factor was not entered as a variable in our analyses). The goal of this experiment was to establish the basic pattern of the effects of key replacement on typing performance to guide our design of the subsequent experiments.

Experiments 2-4 used the same task but addressed the acquisition of letter-key associations by examining typing performance over blocks of trials. These experiments consisted of two phases. In the first phase (training phase), typists typed a small set of words (12 or 18 words) repeatedly over 8 or 10 blocks of 72 trials each, using a single pair of target key and substituted key locations. In the second phase (transfer phase), we manipulated several factors across three experiments. In the transfer phase of Experiment 2, target key was moved back to the original position on the keyboard, and we assessed whether a newly acquired letter-key association interfered with typing the original keystroke. We ex- 


\section{$\mathrm{R}$ target}

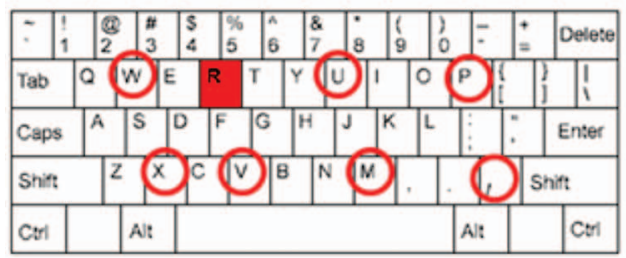

N Target

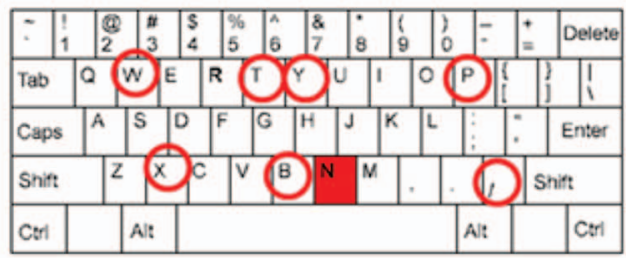

S Target

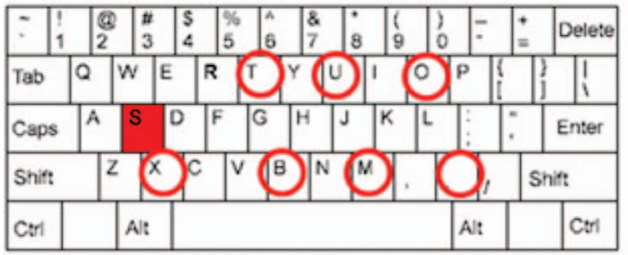

L Target

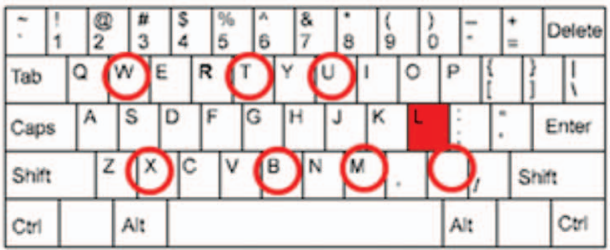

Figure 2. Target letters (grayed keys [red in the online version of the article]) and switched key positions (circled keys) used in Experiments 1-4. See the online article for the color version of this figure.

amined the interference in RT and IKSI to assess influences on the outer loop and the inner loop.

In the transfer phase of Experiment 3, we replaced the trained word set with a new word set to distinguish the roles of the wordand letter-level processes in acquisition of new letter-key associations. The transfer phase of Experiment 4 was similar to that of Experiment 3, but we manipulated digraphs (i.e., letter pairs) to reveal the role of the digraph-level process. In Experiment 4, we systematically varied the contingency between target and a letter that preceded the target (pre-target letter) and between target and a letter that follows the target (post-target letter), which allowed us to dissociate the hierarchical control model and the recurrent network model. Together, the results of the present experiments provide insight into the way people acquire and control skills that involve production of sequential actions.

\section{Experiment 1}

The main purpose of Experiment 1 was to establish the basic pattern of interference caused by a replacement of a target key location. We chose four target keys (R, L, S, and N) corresponding to frequent consonants, two of which are assigned to the index and ring fingers of the left hand, and two of which are assigned to the index and ring fingers of the right hand. Note that four different target locations were used to counterbalance possible confounding factors unique to particular targets (e.g., finger, hand, etc.). The data were aggregated across these target keys and analyzed together. For each target key, there were eight key locations that were substituted for the target key location (including the original location). These locations are depicted in Figure 2. On each trial, typists saw a single word on the computer screen and typed it as quickly and as accurately as possible. Words consisted of five or six letters, in which the target letter appeared only once at the first, third, or fifth position. Letters whose key locations were substituted for the target key location never appeared in any of the words (e.g., the letter W did not occur in the condition where the location of "R" was substituted with that of "W").

The main analyses focused on key switch cost. Key switch cost was defined by the difference between RT or IKSI for the conditions in which the target key was at the original location and RT or IKSI for the condition in which the target key was moved to a new location. According to the two-loop theory (Logan \& Crump, 2011), each keystroke is controlled by inner-loop processing. However, outer-loop processing would be required to control keystrokes for letters whose locations are switched if the letterkey associations are not strong enough to allow the inner loop to operate by itself. Hence, key switch cost reflects the involvement of the outer loop in the respective keystrokes. Key switch cost will appear in RT if the target is the first letter of the word and IKSI if the target is a subsequent letter.

\section{Method}

Participants. Twenty four touch typists were recruited from the Vanderbilt University community. They were either given experimental credit for their psychology courses or paid $\$ 12$ for participation. All typists were recruited with the following criteria: (a) they should be capable of touch-typing with 10 fingers with the conventional finger placement on the keyboard, (b) be able to type more than 50 words per minute (WPM), (c) have English as their first language, (d) have no speech or hearing disorders, and (e) have normal or corrected-to-normal visual acuity. Typing speed was measured by using a typing test (see Logan \& Zbrodoff, 1998, for details) administered at the beginning of the session. Their mean typing speed was 86.10 word per minute (WPM; $S D=$ $18.24)$ and typing accuracy was $94.59 \%(S D=3.39)$. These typists also filled out post-experiment questionnaires regarding their typing experiences, which indicated that they had a mean of 5.73 months $(S D=7.42)$ of formal typing training and 12.60 years 
$(S D=3.99)$ of typing experience, and spent $4.98 \mathrm{hr}$ per day $(S D=$ 2.81) in front of a computer.

Apparatus and stimuli. The apparatus consisted of a desktop computer and a 19-in. (48.26-cm) CRT monitor. Responses were registered by using a regular QWERTY keyboard. Black stickers were placed on the surfaces of the keys to hide the letter labels. Stimuli were 5- or 6-letter words, which were obtained from the MRCPsycholinguistic Database(Coltheart, 1981; http://www.psych .rl.ac.uk/). The frequencies of these words per million were obtained from the Corpus of Contemporary American English (Davies, 2010; http://corpus.byu.edu/coca/). A target letter appeared once in all words at either the first, third, or fifth letter position, and any of the possible letters to which the target was switched never appeared in these words. There were four possible target letters, manipulated between subjects, and for each target, there were seven possible letters to be switched to (see Figure 2). Also, for each target, 15 words were prepared for each combination of target position in a word (first, third, and fifth position) and word length (5 and 6 letters). These words were selected such that they did not contain letters that corresponded to the seven possible key locations to which the target key location was substituted. Word frequencies of these lists were submitted to an ANOVA, which revealed no significant difference, $F(23,336)<1, M S E=30.77$. The actual word stimuli and their frequencies are shown in the online supplemental materials. The word stimuli were presented in lower case at the center of screen in the Courier New font in the font size of $24 \mathrm{pt}$. They were printed in black against a white background.

Procedure. Typists were tested individually in a cubicle under normal fluorescent lighting. They sat in front of the computer monitor at an unrestricted viewing distance of $55 \mathrm{~cm}$ and read on-screen instructions. Each typist performed eight blocks of test trials, for which the position of a target key was moved to one of the eight key positions (including the original target key position). There were four possible target keys ("R," "N," "S," and "L"), and typists were randomly assigned to one of the targets with a restriction that there would be six typists assigned to each target. The eight key positions to which the target key was moved differed slightly across the targets, and they are shown in Figure 2. These positions were chosen to vary three parameters of keystrokes systematically; hand, finger, and row on the keyboard. For instance, for the target "R," one of the key positions ("V") required a keystroke with the same finger and the same hand but in the lower row, whereas the other key position ("W") required a keystroke with a different finger but the same hand in the upper row.

The order of the eight blocks was randomly determined for each subject. For each block, there were six practice trials and 90 test trials, in which the three letter positions in word (1st, 3rd, and 5th positions) and the two word lengths ( 5 letters, 6 letters) occurred randomly and equally frequently. Each block was preceded by an instruction screen that informed the position of the target key in the block; the QWERTY keyboard layout (as shown in Figure 2) was displayed on the screen, whereby a new target key position was highlighted in red.

A trial started with a fixation cross at the center of screen for $500 \mathrm{~ms}$. The cross was replaced by a word. Typists typed the word as soon as a word appeared on the screen. The intervals between the word onset and the respective keystrokes were recorded. RT was defined as the interval between word onset and the first keystroke, and IKSI was the intervals between successive keystrokes. A trial was considered correct only if all letters were typed correctly. The typed letters were echoed on the display below the word stimulus in lower case. The trial ended when subjects made as many keystrokes as the number of letters in the word or when 5,000 ms elapsed after word onset. The message "Error!" printed in red, was presented at the screen center for $500 \mathrm{~ms}$ for error trials. If typists did not make five or six keystrokes within 5,000 ms, the message "Too Slow" appeared at the screen center for 500 ms. For correct trials, the stimulus and typed words remained on the display for $500 \mathrm{~ms}$ after the fifth keystroke. The fixation cross replaced the display, signaling the beginning of the next trial.

\section{Results}

We discarded trials in which typists did not complete a whole word $(0.21 \%)$ and trials in which RT was less than $200 \mathrm{~ms}$ or greater than $2000 \mathrm{~ms}(0.20 \%)$. Mean RT and IKSI for correct responses, and percentage of errors (PE) were computed for each typist (see the Appendix). Switch costs were computed by subtracting RT and IKSI for blocks in which the target key was at the original location from RT and IKSI for blocks in which the target key was at a new location.

Figure $3 \mathrm{~A}$ shows key switch cost for three target positions (1st, 3rd, and 5th) as a function of keystroke position. Figure 3B summarizes the same key switch cost differently: In that figure, the horizontal axis represents keystroke positions relative to the target keystroke. Thus, $\mathrm{T}+1$ indicates that it is one keystroke after the target, whereas $\mathrm{T}-1$ indicates that it is one keystroke before the target (e.g., for the word "scream" with the target R, $\mathrm{T}+1$ is the letter "e" and $\mathrm{T}-1$ is the letter "c"). Note that switch costs for the first keystroke (in RT) are shown as open symbols in Figure $3 \mathrm{~B}$ (at $\mathrm{T}$ when the target was the 1 st position, $\mathrm{T}-2$ when the target was at the 3 rd position, and $\mathrm{T}-4$ when the target was at the 5 th position).

The profiles of switch costs look very similar across keystroke positions (see Figure 3B). In general, key switch cost increased gradually before the target keystroke $(27 \mathrm{~ms}$ at $\mathrm{T}-3,45 \mathrm{~ms}$ at $\mathrm{T}-2$, and $48 \mathrm{~ms}$ at $\mathrm{T}-1)$, peaked at the target keystroke (169 $\mathrm{ms}$ at $\mathrm{T})$, and decreased gradually after the target keystroke $(80 \mathrm{~ms}$ at $\mathrm{T}+1,21 \mathrm{~ms}$, at $\mathrm{T}+2,16 \mathrm{~ms}$ at $\mathrm{T}+3$, and $12 \mathrm{~ms}$ at $\mathrm{T}+4$, and $10 \mathrm{~ms}$ at $\mathrm{T}+5)$. These values were all significantly different from zero $(p s<.002)$. The increase of switch cost from $\mathrm{T}-3$ to $\mathrm{T}-1$ is significant, as confirmed by a repeated-measures ANOVA $(\mathrm{T}-3$ vs. $\mathrm{T}-2$ vs. $\mathrm{T}-1), F(2,46)=14.39, M S E=$ 222, $p<.001, \eta_{\mathrm{p}}^{2}=.385$. The decrease of switch cost from $\mathrm{T}+$ 1 to $\mathrm{T}+5$ is also significant, as confirmed by an ANOVA $(\mathrm{T}+$ 1 vs. $\mathrm{T}+2$ vs. $\mathrm{T}+3$ vs. $\mathrm{T}+4$ vs. $\mathrm{T}+5), F(4,92)=94.05$, $M S E=217, p<.001, \eta_{\mathrm{p}}^{2}=.804$.

Key switch cost at target keystroke was similar across the three target positions, except when target was at the 5th letter of fiveletter words, which was the last letter of a word: switch cost was smaller $(M=110 \mathrm{~ms})$ in that condition than others $(M \mathrm{~s}=176$ and $178 \mathrm{~ms}$ for the $1 \mathrm{st}$ and $3 \mathrm{rd}$ letter positions of five-letter words; $M \mathrm{~s}=180,187$, and $184 \mathrm{~ms}$ for the 1st, 3rd, and 5th letter positions of six-letter words). To confirm this observation, we submitted key switch cost to a one-way repeated-measures ANOVA, whose result was significant, $F(5,115)=8.02, M S E=2,552, p<.001$, $\eta_{\mathrm{p}}^{2}=.258$. Bonferroni adjusted simple pairwise contrasts showed 
A

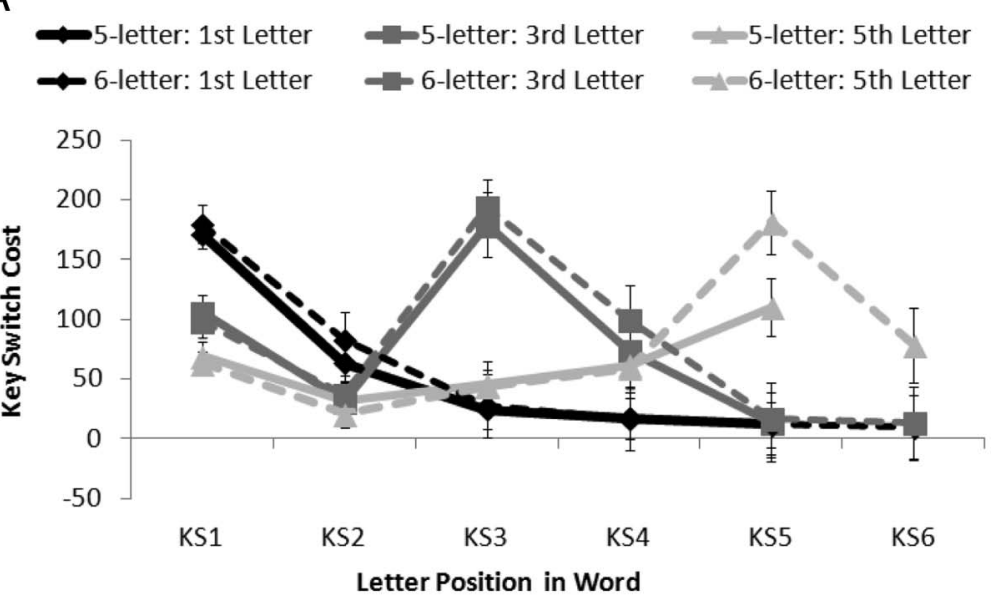

B

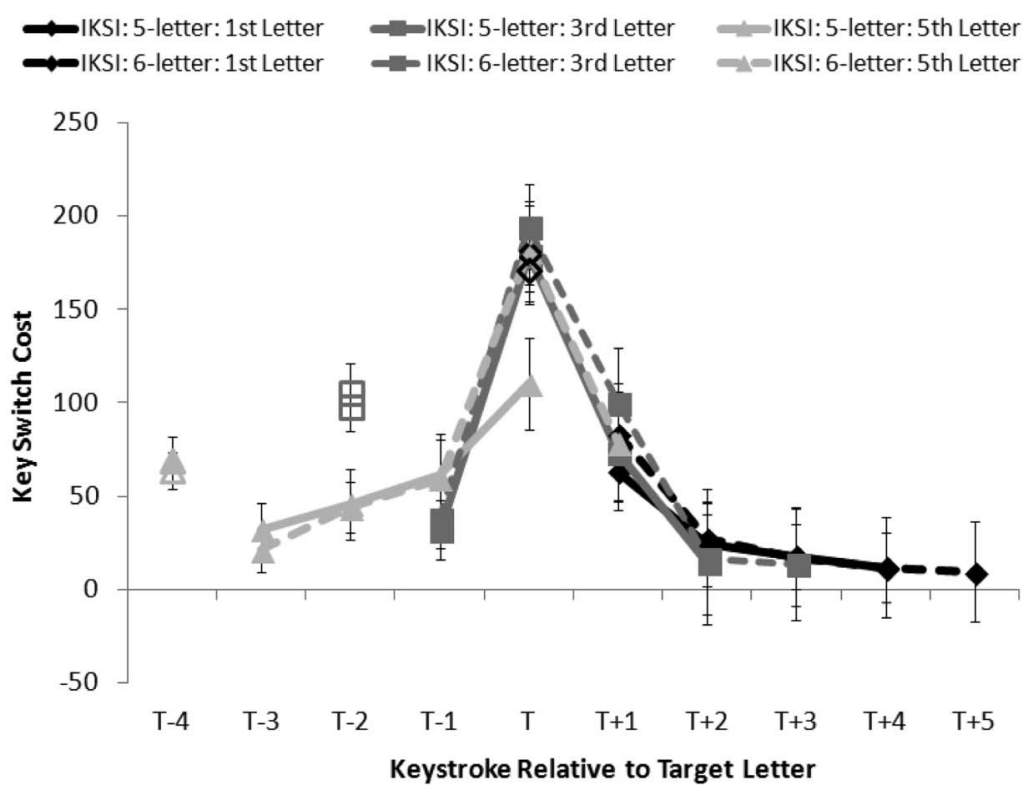

Figure 3. Key switch cost at each keystroke (KS) in five- and six-letter words (A) as a function of KS position in word and (B) as a function of KS relative to the target letter in Experiment 1. In Panel B, open shapes represent key switch costs in response time, and filled shapes connected by lines or dotted lines represent key switch costs in interkeystroke interval (IKSI). $\mathrm{T}=$ target keystroke; $\mathrm{T}-n=n$ keystrokes before target; $\mathrm{T}+n=n$ keystrokes after target. Error bars represent the standard error of the means.

that 5 th position for five-letter words differed from others $(p s<$ $.003)$, but the other conditions did not differ from each other.

Key switch costs seemed larger before the target keystroke than after the target. To examine this impression, we compared key switch costs at $\mathrm{T}+1, \mathrm{~T}+2$, and $\mathrm{T}+3$, for the 1 st letter position with key switch costs at $\mathrm{T}-3, \mathrm{~T}-2$, and $\mathrm{T}-1$, for the 5th letter position, respectively, with paired $t$-tests (averaged across two word lengths $).{ }^{1}$ Although switch cost at $\mathrm{T}+1(M=73 \mathrm{~ms})$ was not significantly different from that at $\mathrm{T}-1(M=60 \mathrm{~ms}), t(23)=$ 1.37, switch costs at $\mathrm{T}+2(M=26 \mathrm{~ms})$ and $\mathrm{T}+3(M=17 \mathrm{~ms})$ were smaller than those at $\mathrm{T}-2(M=45 \mathrm{~ms})$ and $\mathrm{T}-3(M=$ $27 \mathrm{~ms}$ ), respectively, $t \mathrm{~s}>2.4, p \mathrm{~s}<.024$. These outcomes suggest that switch costs are not symmetric before and after the target keystroke.

\section{Discussion}

The main result of the present experiment is shown in the pattern of interference in surrounding the target keystroke: Key switch cost was largest at the target keystroke and decreased as keystroke moved away from the target (see Figure 3B). As we suggested in the Introduction, key switch cost reflects an involve-

\footnotetext{
${ }^{1}$ We thank Matt Crump for suggesting this analysis.
} 
ment of the outer loop because the new letter-key association is not strong enough to be implemented by the inner loop. Thus, the pattern of key switch cost observed in the present experiment implies that the closer a keystroke is to the target letter, the more likely the outer loop is to be involved in implementing that keystroke. We can estimate the likelihood of outer-loop involvement in each keystroke based on the proportion of switch cost at each keystroke to switch cost at the target keystroke, which resulted in estimated percentages of outer-loop involvement (= switch cost/switch cost at $\mathrm{T} \times 100)$ of $16 \%$ at $\mathrm{T}-3,27 \%$ at $\mathrm{T}-$ $2,28 \%$ at $\mathrm{T}-1,100 \%$ at $\mathrm{T}, 47 \%$ at $\mathrm{T}+1,12 \%$ at $\mathrm{T}+2$, and $9 \%$ at $\mathrm{T}+3$. The percentage is particularly large at $\mathrm{T}+1$. This is reasonable because the outer loop is likely to be involved in typing letters that follow the target, and $T+1$ is the first letter after the target. The percentage drops quickly after $\mathrm{T}+1$, suggesting that the inner loop takes over once the sequence is restarted. Furthermore, we compared switch costs before and after the target keystroke for the 1st and 5th letter positions and found that switch cost was larger before the target than after the target. This result also implies that the inner loop takes over quickly once an unfamiliar target keystroke has been executed.

Figure 3B shows switch costs aligned with respect to the position of the target keystroke in the word. Switch costs from different target positions and word lengths fall on a single function that peaks at the target position. Switch costs in RT (indicated by unfilled symbols in the figure) fall above this function. This suggests that something more than keystroke processing contributes to switch costs in RT. Word-level planning in the outer loop is a likely possibility (see Yamaguchi \& Logan, 2014).

In the present experiment, we used four different target letters, each substituted with seven key locations making up a total of 28 switch conditions. Although not reported here, we assessed these conditions separately and observed that the patterns of interference were essentially the same for all conditions. Therefore, the results represent robust patterns of the interference resulting from disabling a familiar letter-key association in skilled typewriting. In the subsequent experiments, we investigated acquisition of a new letter-key association using the key switch procedure.

\section{Experiment 2}

The results of Experiment 1 suggested that the key switch procedure forces the outer loop to deal with the target keystroke. Switching key locations breaks familiar letter-key associations, so the inner loop cannot translate the letter to the corresponding keystroke automatically, making skilled typing unskilled. Experiment 1 also suggested that disabling familiar letter-key associations affected word-level planning in the outer loop. The main purpose of Experiment 2 was to investigate the process of acquiring new letter-key associations and the influence of the newly acquired associations on outer-loop and inner-loop processing.

Experiment 2 consisted of two phases; in the first phase (training phase), typists typed a set of 18 six-letter words presented repeatedly during eight blocks of 72 trials (each word appeared four times in a random order in each block for a total of 32 presentations). For each typist, the target key was moved to a new key location during the training phase. We expected that key switch costs would decrease over blocks, reflecting learning in the outer loop, the inner loop, or both. To determine the locus of learning, we moved the target key back to the original location in the second phase (transfer phase), and assessed the cost of the new letter-key association in the execution of the original keystroke.

If the learning occurred in the inner loop, strengthening the new letter-key associations, it should interfere with the original letterkey mapping in the transfer phase, slowing keystroke latency. If the learning occurred in the outer loop, improving its efficiency in controlling the new keystroke, there should be no interference in the transfer phase. However, learning is often context-specific (e.g., Crump, Vaquero, \& Milliken, 2008; Yamaguchi \& Proctor, 2009), so the new letter-key associations may be utilized only in the context that cues switching of key locations, and not in the context of normal typing. Thus, it is possible that no interference would be obtained in the transfer phase even when new associations had been learned in the training phase.

\section{Method}

Participants. Twenty-four skilled typists were recruited from the same subject pool as in Experiment 1, with the same criteria for subject selection. Their mean typing rate was 77.53 WPM ( $S D=$ $19.49)$ and mean accuracy was $91.58 \%(S D=6.56)$. They had 12.04 years $(S D=3.82)$ of experience in typing and 6.02 months $(S D=7.05)$ of formal training on average. They reported sitting in front of computer for $3.45 \mathrm{hr}(S D=1.67)$ per day.

Apparatus and stimuli. The apparatus was the same as that used in Experiment 1, but new word lists were constructed. There were three lists of 18 words for each of the 24 typists (a total of 72 lists), each list consisting of six 6-letter words for which the target letter ( $\mathrm{R}, \mathrm{N}, \mathrm{S}$, or $\mathrm{L}$ ) was at the first, third, or fifth letter position. These words did not include a letter corresponding to a new target position. The new target position was one of the six letters for the respective target letters (see Figure 2). Note that we excluded the slash ("/") and period (".") from the possible new key locations.

One of the three lists was used for the practice phase of the experiment (Block 1), and the second list was used for the training phase (Blocks 2-10) and for the transfer phase (Blocks 11-12). The third list was prepared for the transfer phase in Experiment 3, so it was not used in the present experiment. Word frequency was equated across 24 typists, 3 word lists, and 3 target positions (comprising 216 lists of six words each), supported by the null effect in a one-way ANOVA on word frequencies of these lists, $F(215,1080)<1, M S E=721.86(M=27.59$ per million, $S D=$ 4.11, range of $M \mathrm{~s}=19.24-41.46)$. All word lists used in the present experiment are shown in the online supplemental materials.

Procedure. Each typist performed 12 blocks of 72 trials, each consisting of four cycles of 18 unique words. The first block (Block 1) was considered to be warm-up and was not included in the analysis reported below. The second block (Block 2) served as the baseline of typing performance. The next eight blocks (Blocks 3-10) were training blocks in which the target key was moved to a new location. The last two blocks (Blocks 11-12) constituted the transfer phase, in which typists used the original target key location. The word list used in the transfer phase was the same as that used in the training phase. The procedure was essentially the same as that of Experiment 1 in other respects. 


\section{Results}

As in Experiment 1, trials for which typists did not complete typing the whole word $(0.26 \%)$ and for which RT was less than $200 \mathrm{~ms}$ or greater than $2,000 \mathrm{~ms}(0.29 \%)$ were eliminated. Mean RT and IKSI for correct trials and PE were computed for each typist. Mean RTs and IKSIs at target keystrokes in each block are presented in the Appendix.

Our analysis focused on key switch cost as a function of trial block, which were defined as the differences in RT or IKSI in the respective trial blocks from the baseline (i.e., RT or IKSI in Block 2 , where the target key was still at the original position). We report the analyses of key switch cost in RT and key switch cost in IKSI at the target keystroke (see Figure 4; see the Appendix for the analysis of key switch cost in PE).

We conducted two separate analyses. The first analysis examined key switch costs in the training phase to assess whether learning took place in the course of eight training blocks with a new target key position. The second analysis examined switch cost in the transfer phase to assess interference in the original letterkey association from newly acquired one.

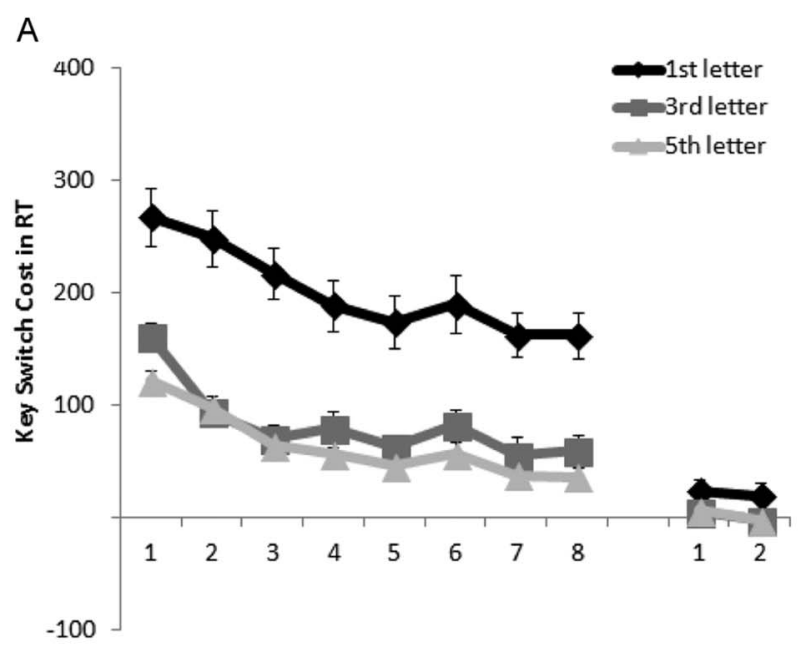

B

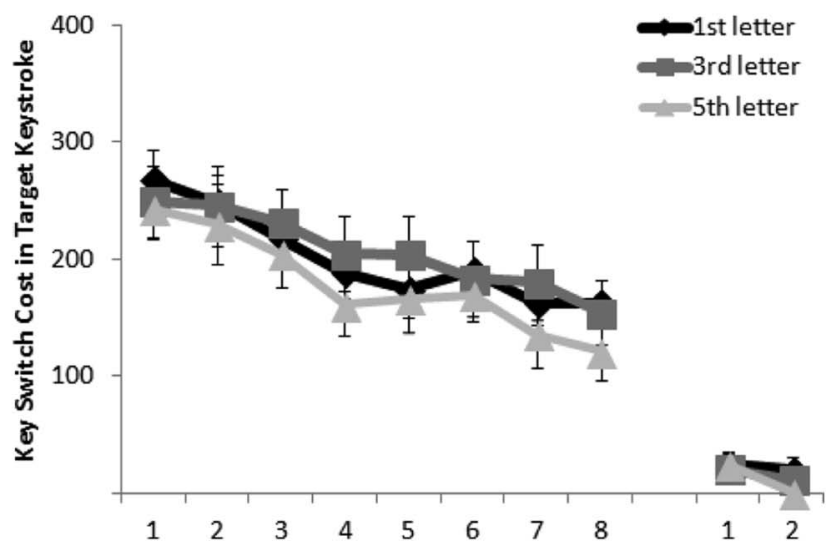

Figure 4. Key switch cost in (A) response time (RT) and (B) target keystroke as a function of trial block in Experiment 2. Error bars represent the standard error of the means.
Training phase. Key switch cost in RT (see Figure 4A) depended on the target letter position in words. Averaged over training blocks, cost was largest when target was the first letter $(M=202 \mathrm{~ms})$, intermediate when it was the third letter $(M=$ $83 \mathrm{~ms})$, and smallest when it was the fifth letter $(M=65 \mathrm{~ms})$. These outcomes agree with the results of Experiment 1 (see the Appendix). Switch cost became smaller over blocks, starting from $184 \mathrm{~ms}$ in the first training block and decreasing to $86 \mathrm{~ms}$ in the last block. A similar pattern of reduction in switch cost was observed for all three target positions, but it was larger when target was the first letter $(M=106 \mathrm{~ms})$ or the third letter $(M=102 \mathrm{~ms})$ than when target was the fifth letter $(M=85$ $\mathrm{ms}$ ). These observations are supported statistically by a 3 (Target Position: 1st, 3rd, and 5th) $\times 8$ (Trial Block) ANOVA (see Table 1), which revealed main effects of Target Position, Trial Block, and their interaction.

There were large switch costs at the target keystroke (see Figure 4B) for the three target positions $(M \mathrm{~s}=268,250$, and $243 \mathrm{~ms}$, for the 1st, 3rd, and 5th positions, respectively), but these costs decreased over blocks by 106, 96, and $122 \mathrm{~ms}$, for the 1st, 3rd, and 5th letter positions, respectively. A 3 (Target Position: 1st, 3rd, and 5th) $\times 8$ (Trial Block) ANOVA (see Table 1) indicated that the only significant effect was Trial Block, reflecting reductions of switch cost over blocks (see Figure 4).

Cost of new letter-key association in the original keystroke. In the transfer phase, all keys were in their original positions on the keyboard. Hence, "key switch costs" would represent interference with the original keystroke from newly learned letterkey associations. Switch cost in RT was only $12 \mathrm{~ms}$ overall in the first block of the transfer phase, which is remarkably smaller than switch cost in the last block of the training phase $(M=86 \mathrm{~ms})$. The cost was mostly attributable to trials in which target was the first letter $(M=24 \mathrm{~ms})$, one-sample $t(23)=$ $2.20, p<.038$, and it was virtually non-existent when target was the third letter $(M=6 \mathrm{~ms})$ or fifth letter $(M=7 \mathrm{~ms}), t \mathrm{~s}<$ .7. Indeed, switch costs at the target keystrokes were similar for the three target positions $(M \mathrm{~s}=24,21$, and $25 \mathrm{~ms}$, for the $1 \mathrm{st}$, $3 \mathrm{rd}$, and 5th letter positions), and they were all statistically significant, $t \mathrm{~s}>2.20, \mathrm{ps}<.038$. We examined whether nontarget keystrokes were also slowed in the transfer phase, to determine whether the key switch cost in the original keystroke was due to general slowing in the transfer phase. We computed key switch cost for non-target keystrokes in the same manner as that for target keystrokes and found that the costs were all negative $(M \mathrm{~s}=-7 \mathrm{~ms},-4 \mathrm{~ms}$, and $-10 \mathrm{~ms}$, for the $1 \mathrm{st}, 3 \mathrm{rd}$, and 5 th letter positions), suggesting that the switch costs in target keystrokes were not due to general slowing in the transfer phase. Instead, the results imply that newly acquired letter-key associations did interfere with execution of the original keystroke.

Nevertheless, this interference was short-lived, switch costs were not significant in the second block of the transfer phase ( $M \mathrm{~s}=20,11$, and $1 \mathrm{~ms}$, for the 1st, 3rd, and 5th letter positions). This observation is supported by a 3 (Target Position: 1st, 3rd, and 5th) $\times 8$ (Trial Block; 1st vs. 2nd blocks of the transfer phase) ANOVA, which showed a main effect of Trial Block, $F(1,23)=$ $5.60, M S E=1,011, p<.027, \eta_{\mathrm{p}}^{2}=.196$, but no effect involving Target Position. 
Table 1

Analysis of Variance Table for Key Switch Cost in the Transfer Phase of Experiment 2 as a Function of Target Position (TP; 1st, 3rd, 5th) and Trial Block (TB; Blocks 1-8)

\begin{tabular}{|c|c|c|c|c|}
\hline Factor & $d f \mathrm{~s}$ & $F$ & $M S E$ & $\eta_{\mathrm{p}}^{2}$ \\
\hline & \multicolumn{4}{|c|}{ RT } \\
\hline $\mathrm{TP}$ & 2,46 & $33.61^{* *}$ & 31,500 & .594 \\
\hline $\mathrm{TB}$ & 7,161 & $22.69^{* * *}$ & 81,280 & .497 \\
\hline \multirow[t]{2}{*}{$\mathrm{TP} \times \mathrm{TB}$} & 14,322 & $1.92^{*}$ & 2,842 & .077 \\
\hline & \multicolumn{4}{|c|}{ Target keystroke } \\
\hline $\mathrm{TP}$ & 2,46 & 1.07 & 39,053 & .045 \\
\hline TB & 7,161 & $21.43^{* * *}$ & 4,909 & .482 \\
\hline $\mathrm{TP} \times \mathrm{TB}$ & 14,322 & $<1$ & 2,431 & .040 \\
\hline
\end{tabular}

Note. $\mathrm{RT}=$ response time.

${ }^{*} p<.05 .{ }^{* *} p<.001$

\section{Discussion}

As expected, Experiment 2 demonstrated reductions in key switch cost in RT and IKSI when typists typed a set of words over eight blocks of trials. Key switch cost in RT was larger when the target letter occurred earlier in a word than when it occurred later, as we observed in Experiment 1. Nevertheless, the reduction of key switch cost at the target keystroke was similar for the three target positions, implying that learning took place mainly at the letter level in the inner loop. In the transfer phase where the target key was moved back to the original position, we obtained interference with the target keystroke, consistent with learning in the inner loop. The interference in RT was driven mainly by target letters in the first position, where RT included outer- and innerloop processing time for the target keystroke. There was no interference in RT when the target was a subsequent keystroke, where RT included outer- and inner-loop processing time for a non-target keystroke. This suggests that interference with the first keystroke from a new letter-key association did not result from the outer loop. Therefore, we conclude that the newly acquired letter-key associations interfered with the execution of the target keystroke in the inner loop, but not with the planning of keystrokes in the outer loop. We cannot rule out the possibility that context-specific learning occurred in the outer loop during training, which was not expressed in transfer because the context changed (Crump et al., 2008; Yamaguchi \& Proctor, 2009).

The interference from the new letter-key association dissipated quickly. Typists were able to return to the original letter-key association after typing only 72 words or so. The outcome is consistent with Healy, Wohldmann, and Bourne's (2011) finding that learning of new control mappings of a computer mouse influenced performance with the original mappings only for a short time.

\section{Experiment 3}

Experiment 3 aimed at revealing the levels of linguistic units in which the acquisition of new letter-key associations takes place. In this experiment, we intended to separate the contributions of two levels of linguistic units, words and letters. The procedure was similar to that of Experiment 2, but the main manipulation was to change the words in the transfer phase: the target key remained at a new position, but typists typed a set of new words that never appeared in the training phase.

The main comparison was between key switch costs for old words in the last block of the training phase and new words in the first block of the transfer phase. Experiment 2 suggested that the new letter-key association is based on learning at the letter level. If learning takes place only at the letter level, there should be no difference in switch costs for old and new words, so there should be no difference between the last training block and the transfer block. However, if there is any learning at the word level, key switch cost should be larger for new words than for old words, so switch costs should be greater in the transfer block than in the last training block. We can also assess letter-level learning by comparing switch costs in the first training block and the first transfer block: new words are introduced in both of these blocks, so there should be no contribution of word-level learning. Figure 5 shows the decomposition of key switch cost into word- and letter-level learning.

\section{Method}

Participants. A new group of 24 skilled typists were recruited using the same criteria for subject selection in Experiment 1. Their mean typing rate was $85.83 \mathrm{WPM}(S D=17.58)$ and mean accuracy was $92.85 \%(S D=4.56)$. They had 11.88 years $(S D=3.19)$ of typing experience and 4.68 months $(S D=2.96)$ of formal training. They also reported using a computer $4.19 \mathrm{hr}(S D=1.91)$ on average per day.

Apparatus and stimuli. The apparatus was the same as that used in Experiment 2. The words for the training phase were based on those used in Experiment 2, but there was an additional word list of 18 new words for each typist that was used in the transfer phase (Blocks 11-12) of the present experiment. Thus, there were three separate lists of 18 words for each typist, which made up a total of 72 lists $(24$ typists $\times 3$ lists; see the online supplemental materials).

Procedure. The procedure was essentially the same as that of Experiment 2, except that the words in the transfer phase (Blocks

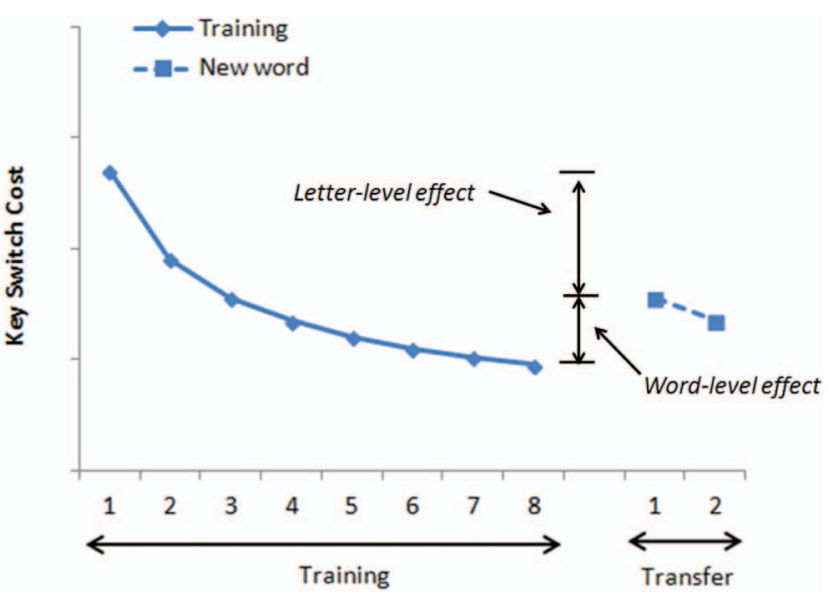

Figure 5. Decomposition of key switch cost into word- and letter-level learning effects in Experiment 3. See the online article for the color version of this figure. 
11 and 12) was different from the words in the baseline block (Block 2) and the training phase (Blocks 3-10). As in Experiment 2 , the first block used a list of 18 words that never appeared in the subsequent blocks, and the data in that block were not analyzed.

\section{Results}

Trials were filtered in the same manner as in Experiment 2 (no response, $0.20 \%$; outliers, $0.28 \%$ ). Mean RTs and IKSIs at target keystrokes in each block are presented in the Appendix. As in Experiment 2, our analysis focused on key switch cost as a function of trial block (see Figure 6). In the present experiment, switch costs were defined as the increases in RT or IKSI in the respective trial blocks from the baseline. We conducted three types of analysis. The first analysis focused on the improvement during the training phase. The second analysis examined word-level learning effects by comparing switch costs in the last block of the training phase and the first block of the transfer phase. The third analysis examined letter-level learning effects by comparing switch costs in the first block of the training phase and the first block of the transfer phase (see Table 2).

Training phase. Averaged over blocks, key switch cost in RT (see Figure 6A) was largest when target was the first letter of a word $(M=182 \mathrm{~ms})$, intermediate when target was the third letter

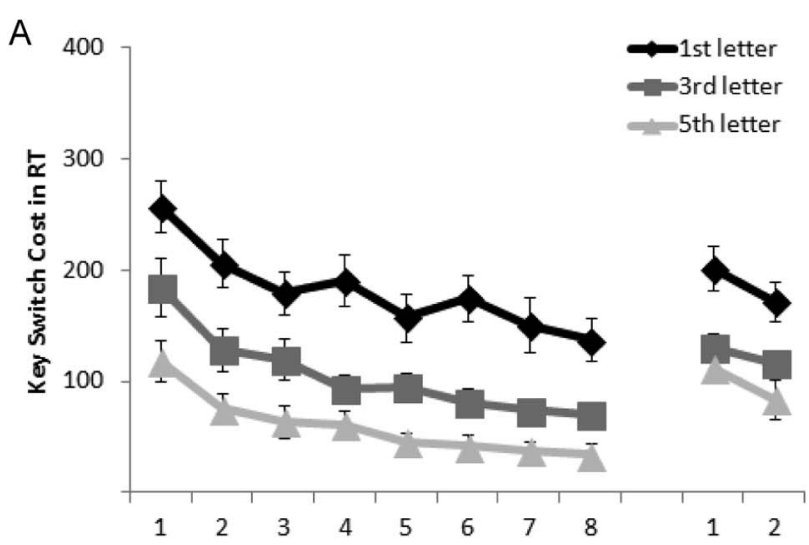

B

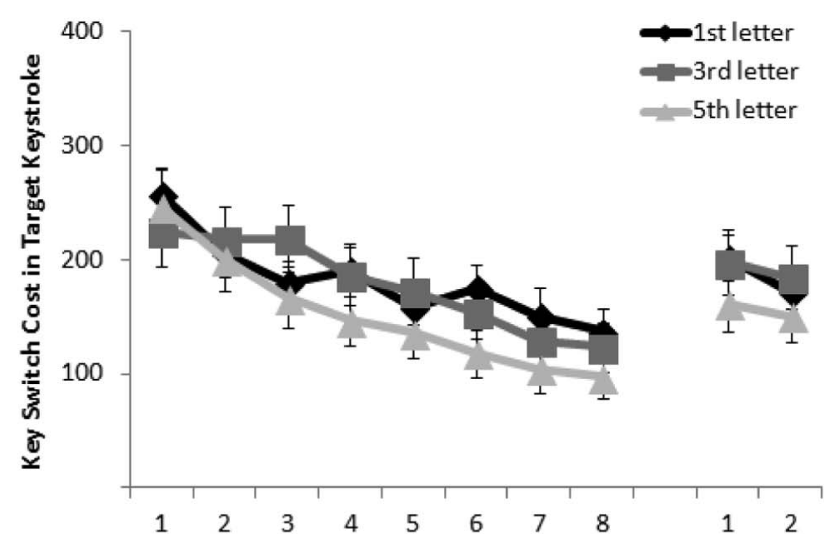

Figure 6. Key switch cost in (A) response time (RT) and (B) target keystroke as a function of trial block in Experiment 3. Error bars represent the standard error of the means.
( $M=106 \mathrm{~ms})$, and smallest when the target was the fifth letter $(M=60 \mathrm{~ms})$. These outcomes are consistent with Experiments 1 and 2 (see the Appendix). Key switch cost decreased steadily over blocks for all target positions. On average, there was a 106-ms reduction in key switch cost from the first block to the last block of the training phase. A 3 (Target Position: 1st, 3rd, and 5th) $\times 8$ (Trial Block) ANOVA (see Table 2) revealed no interaction of Target Position and Trial Block, suggesting that training with new target key locations improved performance similarly for the three target positions.

Key switch cost at the target keystroke showed a reduction of $119 \mathrm{~ms}$ from the first training block to the last when target was the first letter, $101 \mathrm{~ms}$ when target was the third letter, and $149 \mathrm{~ms}$ when target was the fifth letter (see Figure 6B). A 3 (Target Position: 1st, 3rd, and 5th) $\times 8$ (Trial Block) ANOVA (see Table 2) found no significant difference in the size of the switch cost among the three target positions overall $(M \mathrm{~s}=182,193$, and 174 $\mathrm{ms}$, for $1 \mathrm{st}, 3 \mathrm{rd}$, and 5 th letter, respectively).

Transfer phase.

Word-level learning. Key switch cost was larger in the transfer phase than in the last block of the training phase. This increase reflects word-level learning because typists typed a new set of words in the transfer phase (see Figure 5). Key switch cost in RT (see Figure 6A) increased by $68 \mathrm{~ms}$ in the first transfer block from the last training block. Switch cost was largest when target was the first letter, intermediate when it was the third letter, and smallest when it was the fifth letter. A 3 (Target Position) $\times 2$ (Trial Block: last training vs. first transfer) ANOVA, which revealed that significant main effects of Target Position and Trial Block, but no interaction (see Table 2).

Key switch cost at the target keystroke (see Figure 6B) increased in the first transfer block by $67 \mathrm{~ms}$ on average. Thus, the amount of the word-level learning was almost identical for the target keystroke and the first keystroke (in RT). A 3 (Target Position) $\times 2$ (Trial Block: last training vs. first transfer) ANOVA reveal no significant interaction between Trial Block and Target Position (see Table 2).

Letter-level learning. Improvements from the first training block to the first transfer block indicate letter-level learning (see Figure 5). Typists encountered new sets of words in both blocks, so there should be no word-level learning in either block.

Key switch cost in RT (see Figure 6B) was 39 ms smaller in the first transfer block than in the first training block. A 3 (Target Position) $\times 2$ (Trial Block: first training vs. first transfer) ANOVA (see Table 2) found an interaction between Target Position and Trial Block. This interaction suggested that key switch cost was smaller in the first transfer block than in the first training block when the target was the first letter $(M=55 \mathrm{~ms})$ or the third letter ( $M=54 \mathrm{~ms})$, but not when the target was the fifth letter $(M=6$ $\mathrm{ms})$. This indicates that about half of the improvement was due to word-level learning when the target was the first or third letter (there was a 68-ms word-level effect on average). When the target was the fifth letter, the majority of improvement in RT was word-level learning. These findings are interesting, and we elaborate on them in the Discussion section.

Key switch cost at the target keystroke (see Figure 6B) was 56 $\mathrm{ms}$ smaller in the first transfer block than in the first training block. Again, the amount of letter-level learning was almost the same as that when the target was the first or third letter. A 3 (Target 
Table 2

Analysis of Variance Table for Key Switch Cost in the Transfer Phase of Experiment 3 as a Function of Target Position (TP; 1st, 3rd, 5th) and Trial Block (TB; See the Table Notes)

\begin{tabular}{|c|c|c|c|c|c|c|c|c|}
\hline \multirow[b]{2}{*}{ Factor } & \multicolumn{4}{|c|}{ RT } & \multicolumn{4}{|c|}{ Target keystroke } \\
\hline & $d f \mathrm{~s}$ & $F$ & $M S E$ & $\eta_{\mathrm{p}}^{2}$ & $d f \mathrm{~s}$ & $F$ & $M S E$ & $\eta_{\mathrm{p}}^{2}$ \\
\hline $\mathrm{TP}$ & 2,46 & $32.22^{* * *}$ & 22,581 & .584 & 2,46 & $<1$ & 20,762 & .035 \\
\hline $\mathrm{TB}^{\mathrm{a}}$ & 7,161 & $16.48^{* *}$ & 5,029 & .417 & 7,161 & $8.45^{* * *}$ & 4,021 & .269 \\
\hline $\mathrm{TP} \times \mathrm{TB}$ & 14,322 & 1.40 & 1,369 & .057 & 14,322 & $9.68^{* *}$ & 2,965 & .296 \\
\hline TP & 2,46 & $17.09^{* * *}$ & 6,944 & .426 & 2,46 & 3.14 & 6,838 & .120 \\
\hline $\mathrm{TB}^{\mathrm{b}}$ & 1,23 & $87.98^{* * *}$ & 1,865 & .793 & 1,23 & $32.90^{* * *}$ & 4,953 & .589 \\
\hline $\mathrm{TP} \times \mathrm{TB}$ & 2,46 & $<1$ & 2,091 & .022 & 2,46 & $<1$ & 1,605 & .011 \\
\hline TP & 2,46 & $21.12^{* * *}$ & 7,550 & .479 & 2,46 & $<1$ & 10,744 & .032 \\
\hline $\mathrm{TB}^{\mathrm{c}}$ & 1,23 & $4.63^{*}$ & 11,509 & .168 & 1,23 & $20.13^{* *}$ & 5,569 & .467 \\
\hline $\mathrm{TP} \times \mathrm{TB}$ & 2,46 & $3.65^{*}$ & 2,615 & .137 & 2,46 & 2.66 & 3,771 & .104 \\
\hline
\end{tabular}

Note. $\quad \mathrm{RT}=$ response time.

${ }^{\mathrm{a}} \mathrm{TB}$ (1-8 training blocks). ${ }^{\mathrm{b}} \mathrm{TB}$ (last training block vs. first transfer block). ${ }^{\mathrm{c}} \mathrm{TB}$ (first training block vs. first transfer block).

${ }^{*} p<.05$. ${ }^{* *} p<.001$.

Position) $\times 2$ (Trial Block: first training vs. first transfer) ANOVA revealed no significant interaction between Trial Block and Target Position (see Table 2). Note that the lack of interaction can be contrasted with the significant interaction obtained in RT, for which letter-level learning was virtually absent when the target was the fifth letter.

\section{Discussion}

Key switch costs decreased over training blocks, but performance deteriorated when typists typed a new set of words in the transfer phase. This suggests that new letter-key associations depend on word-level learning (see Figure 5). We estimated the amount of word-level learning as $67 \mathrm{~ms}$ based on the difference in key switch cost between the first transfer block and the last training block. There was also evidence of letter-level learning: Key switch costs were 56 ms smaller in the first transfer block than in the first training block. Therefore, acquisition of new letter-key associations involves both word-level and letter-level learning.

The word-level and letter-level learning effects were similar in RT and target keystroke latency, except for when the target was the fifth keystroke, where there was virtually no letter-level learning in RT. Thus, only word-level learning is observed in the outer loop, whereas word-level and letter-level learning are both observed in the inner loop. This issue will be investigated further in Experiment 4.

It is also important to note that although the present experiment dissociated word- and letter-level learning, some of the word-level learning may reflect linguistic units smaller than words and larger than letters, like digraphs (Crump \& Logan, 2010a). To evaluate this possibility, we conducted Experiment 4 in which we manipulated digraphs involving the target letter.

\section{Experiment 4}

The main purpose of Experiment 4 was to dissociate the contributions of three levels of linguistic units-words, digraphs, and letters-in the acquisition of new letter-key associations. The procedure was similar to that of Experiment 3, in which typists practiced with a new target key position in the training phase and transferred to a new set of words in the transfer phase. We introduced stringent control over the letters that occurred before and after the target letters in the training and transfer phases (the pre-target letters and the post-target letters, respectively). There were five conditions in the transfer phase: trained word trials (old words from the training phase), old-old trials (new words with old pre- and post-target letters from the training phase), new-old trials (new words with new pre-target letters and old post-target letters), old-new trials (new words with old pre-target letters and new post-target letters), and new-new trials (new words with new preand post-target letters).

The comparison between trained words and old-old trials reveals word-level learning. The comparisons between old-old and new-old trials, and between old-new and new-new trials, reveal digraph-level learning that involves pre-target letters. The comparisons between old-old and old-new trials, and between new-old and new-new trials, reveal digraph-level learning that involves post-target letters. The comparison between new-new trials and the first training block reveals letter-level learning. Figure 7 shows the decomposition of key switch cost into the three levels of learning.

\section{Method}

Participants. Twenty-four touch-typists were recruited from the same subject pool as in the preceding experiments, applying the same selection criteria. The typists received $\$ 12$ for their participation. Their mean typing speed was 82.05 WPM ( $S D=$ 14.46) with accuracy of $92.53 \%(S D=4.16)$. They reported having 4.36 months $(S D=2.43)$ of formal training in typing and 11.56 years $(S D=3.04)$ of typing experiences. They spent $4.77 \mathrm{hr}$ $(S D=2.02)$ in front of computer per day.

Apparatus, stimuli, and procedure. The apparatus was identical with that used in the preceding experiments. Word lists were newly constructed in order to manipulate repetition of digraphs involving a target letter in the training and transfer phases. As in Experiment 3, all words included a target letter but did not include a letter corresponding to the switched key 


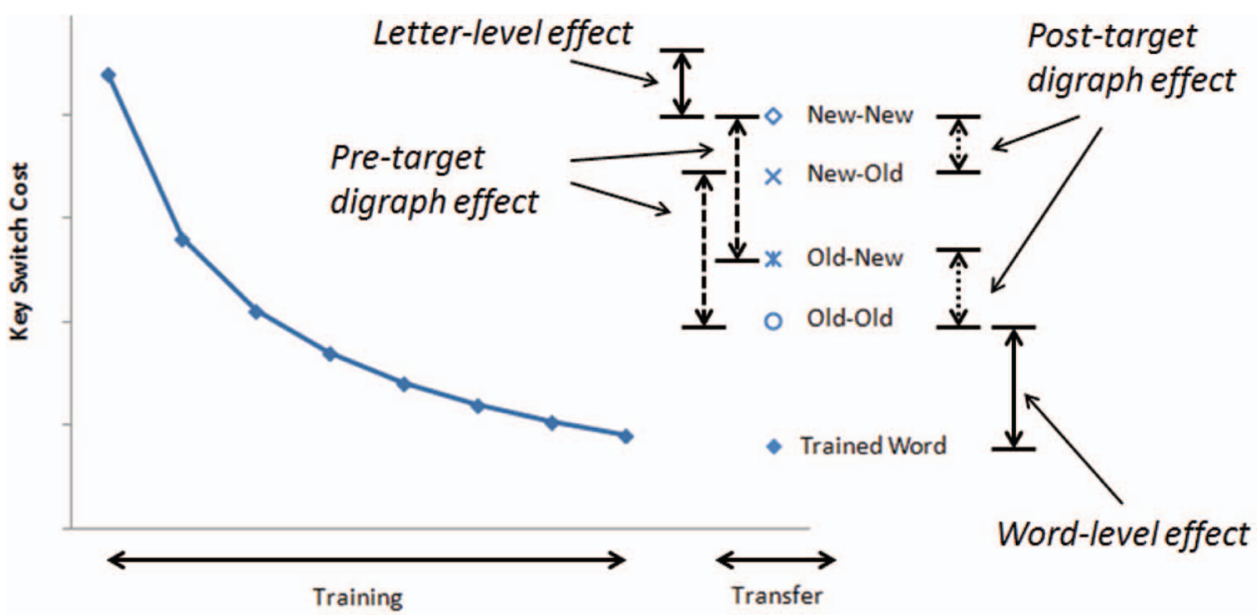

Figure 7. Decomposition of key switch cost into word-, digraph-, and letter-level learning effects in Experiment 4 . See the online article for the color version of this figure.

location. Unlike Experiment 3, the target letter was either the third letter or the fifth letter of the words, but never the first letter. The first letter was excluded so that all trials involved pre-target and post-target digraphs.

There were 12 unique words ( 6 words for each target position) in the practice block and a different set of 12 unique words in the baseline block and in the training blocks. In the transfer phase, there were five different types of word lists that were randomly intermixed. The first type of the lists included the same words as the ones used in the training phase (trained words). The second type included words in which both pre-target and post-target digraphs had occurred in the training phase (old-old words), and the third type included words in which neither pre- nor post-target digraphs had occurred in the training phase (new-new words). The fourth type included words in which pre-target digraph had occurred in the training phase but the posttarget digraph had not (old-new words). The fifth type included words in which post-target digraph had occurred in the training phase but the pre-target digraph had not (new-old words). There were 12 words for each list type (6 words for each target position). The words used in the present experiment can be found in the online supplemental materials.

In the present experiment, there were three possible target letters $(\mathrm{L}, \mathrm{N}$, and $\mathrm{R}$ ) that could be switched in location with a key for one of two alternative letters ( $\mathrm{X}$ or $\mathrm{B}$ for $\mathrm{L}$; $\mathrm{P}$ or $\mathrm{W}$ for $\mathrm{N}$; and $\mathrm{V}$ or $\mathrm{M}$ for $\mathrm{R}$ ). Four typists were assigned to each of the six pairs randomly, and the typists for each pair differed in the word lists used in the training and transfer phases. For each of the six letter pairs, there were four different lists for the training phases, in which two of the lists contained a set of digraphs involving the target (say, Lists A1 and A2), and the other two lists contained another set of digraphs (Lists B1 and B2). For those who received $\mathrm{A} 1$ in the training phase, $\mathrm{A} 1$ and $\mathrm{A} 2$ were used for trained word and old-old word trials, respectively, in the transfer phase, whereas B1 or B2 was used for new-new word trials; for those who received $\mathrm{A} 2$ in the training phase, the role of $\mathrm{A} 1$ and $\mathrm{A} 2$ in the transfer phase were switched. For those who received $\mathrm{B} 1$ or $\mathrm{B} 2$ in the training phase, the role and order of word lists changed, so that all of the four lists served the four roles (i.e., training, trained word, old-old word, and new-new word) equally frequently across typists. In this way, we counterbalanced any characteristics involved in the word lists. Although the words used in the practice phase never occurred in the subsequent trials, those words were also selected to allow only digraphs that could occur in one type of word lists (A1/A2 or B1/B2) to ensure digraphs that appeared in the transfer phase did not occur in the practice phase.

Another set of two word lists were constructed for old-new and new-old word trials. For one list, old-new words were used in $\mathrm{A} 1$ and $\mathrm{A} 2$ whereas new-old words were used in B1 and B2 (say, List $\mathrm{AB}$ ); for the other list, old-new words had appeared in B1 and B2, whereas new-old words were used in A1 and A2 (List BA). Thus, $\mathrm{AB}$ and $\mathrm{BA}$ lists served, respectively, as old-new and new-old word trials for those who received A1 or A2 in the training phase, and as new-old and old-new word trials for those who received B1 or B2 in the training phase. Again, this procedure counterbalanced any characteristics of old-new and new-old word trials across typists. The words in these lists were also carefully selected to equate the overall word frequency of the lists to the word frequency in $\mathrm{A} 1, \mathrm{~A} 2$, $\mathrm{B} 1$, and $\mathrm{B} 2$ all together. Mean frequency for $\mathrm{AB}$ and BA lists were 24.83 per million $(S E=1.85)$, and that for the remaining four list was 27.57 per million $(S E=2.52)$, and they did not differ statistically, $F(1,575)<1, M S E=1,333$ (see the online supplemental materials for the actual word lists used in the present experiment).

The procedure was the same as that of Experiment 3, with minor changes in the numbers of trials. Each typist performed one block of 48 warm-up trials (4 repetitions of 12 words), followed by one block of 48 baseline trials ( 4 repetitions of 12 words). For these blocks, typists typed words using the normal keyboard layout. Then, they proceeded to the training phase consisting of eight blocks of 72 trials (48 repetitions of 12 words) and the transfer phase consisting of two blocks of 120 trials (4 repetitions of 12 words for the five intermixed conditions). During the training and transfer phases, the key location of a target letter was switched to a new key location. 


\section{Results}

Trials were filtered according to the same criteria as in Experiment 3 (no response, $0.79 \%$; outliers, $0.19 \%$ ). The data in the training phase were grouped into 12 blocks of 48 trials. The two transfer blocks were collapsed to make up a group of 48 trials for each of the five transfer conditions. In each of these trial groups, or "blocks," each word appeared 4 times. Mean RTs and IKSIs at target keystrokes for each block appear in the Appendix. The first analysis assessed switch costs in the training phase, and the second analysis assessed switch cost in the transfer phase. Key switch costs in RT and in IKSI at the target keystroke are plotted in Figure 8.

Training phase. Key switch cost in RT (see Figure 8A) decreased from $134 \mathrm{~ms}$ in the first training block to $34 \mathrm{~ms}$ in the last block. Although the cost was larger when target was the third letter $(M=83 \mathrm{~ms})$ than when it was the fifth letter $(M=39 \mathrm{~ms})$, reductions in switch cost were similar for the two target positions $(M \mathrm{~s}=110$ and $91 \mathrm{~ms}$ for the 3rd and 5th letter positions, respectively). A 2 (Target Position: 3rd vs. 5 th) $\times 12$ (Trial Block) ANOVA on key switch cost in RT (see Table 3) supports these observations.

Key switch cost in IKSI at the target keystroke (see Figure 8B) also decreased from $295 \mathrm{~ms}$ in the first training block to $118 \mathrm{~ms}$ in the last block. The cost was larger when target was the third letter ( $M=215 \mathrm{~ms})$ than when it was the fifth letter $(M=157 \mathrm{~ms})$, and there was a larger reduction for the latter condition $(M=209 \mathrm{~ms})$ than for the former $(M=144 \mathrm{~ms})$. A 2 (Target Position: 3rd vs. 5 th) $\times 12$ (Trial Block) ANOVA on key switch cost in IKSI at the target keystroke (see Table 3) supports these observations.

Transfer phase. Key switch cost in RT (see Figure 8A) was smaller for words that were presented in the training phase (trained words) than those that were not, and there was little difference between the two target positions. A 2 (Target Position: 3rd vs. 5th) $\times$ 5 (Trial Type: trained, new-new, new-old, old-new, and old-old) ANOVA confirmed these outcomes (see Table 3). Key switch cost was $99 \mathrm{~ms}$ for new-new words, $97 \mathrm{~ms}$ for new-old words, $93 \mathrm{~ms}$ for old-new words, and $91 \mathrm{~ms}$ for old-old words, which are larger than the 47-ms switch cost for trained words. We computed Fisher's LSD (=31 ms for $p<.05)$ and confirmed that the differences between the four transfer conditions and the trained word trials were significant, but the four transfer conditions did not differ statistically.

To examine letter-level learning, switch costs for new-new trials were compared to switch costs in the first training block in terms of a 2 (Target Position) $\times 2$ (Trial Block) ANOVA, which yielded a marginal effect of Trial Block, $F(1,23)=3.91, p=.059$, and a significant effect of Target Position, $F(1,23)=5.53, p<.028$. Follow-up paired $t$-test indicated that switch cost for the new-new trials was only marginally smaller than the first training block for the 3rd position $(M=52 \mathrm{~ms}), t(23)=2.03, p=.055$, but not for the 5 th position $(M=17 \mathrm{~ms}), t(23)=0.89, p=.383$. The results suggest that switch cost for the first keystroke depended mainly on word-level learning, with little influence of digraph-level and letter-level learning. The conclusion is consistent with Experiment 3.

Key switch cost in ISKI at the target keystroke (see Figure 8B) was also smaller for trained words than the other trials in general. Key switch cost was also smaller when target was the fifth letter $(M=177$ $\mathrm{ms})$ than when it was the third letter $(M=225 \mathrm{~ms})$, but this factor did not influence the differences among the five transfer conditions, as suggested by a 2 (Target Position: 3rd vs. 5th) $\times 5$ (Trial Type: trained, new-new, new-old, old-new, and old-old) ANOVA on key
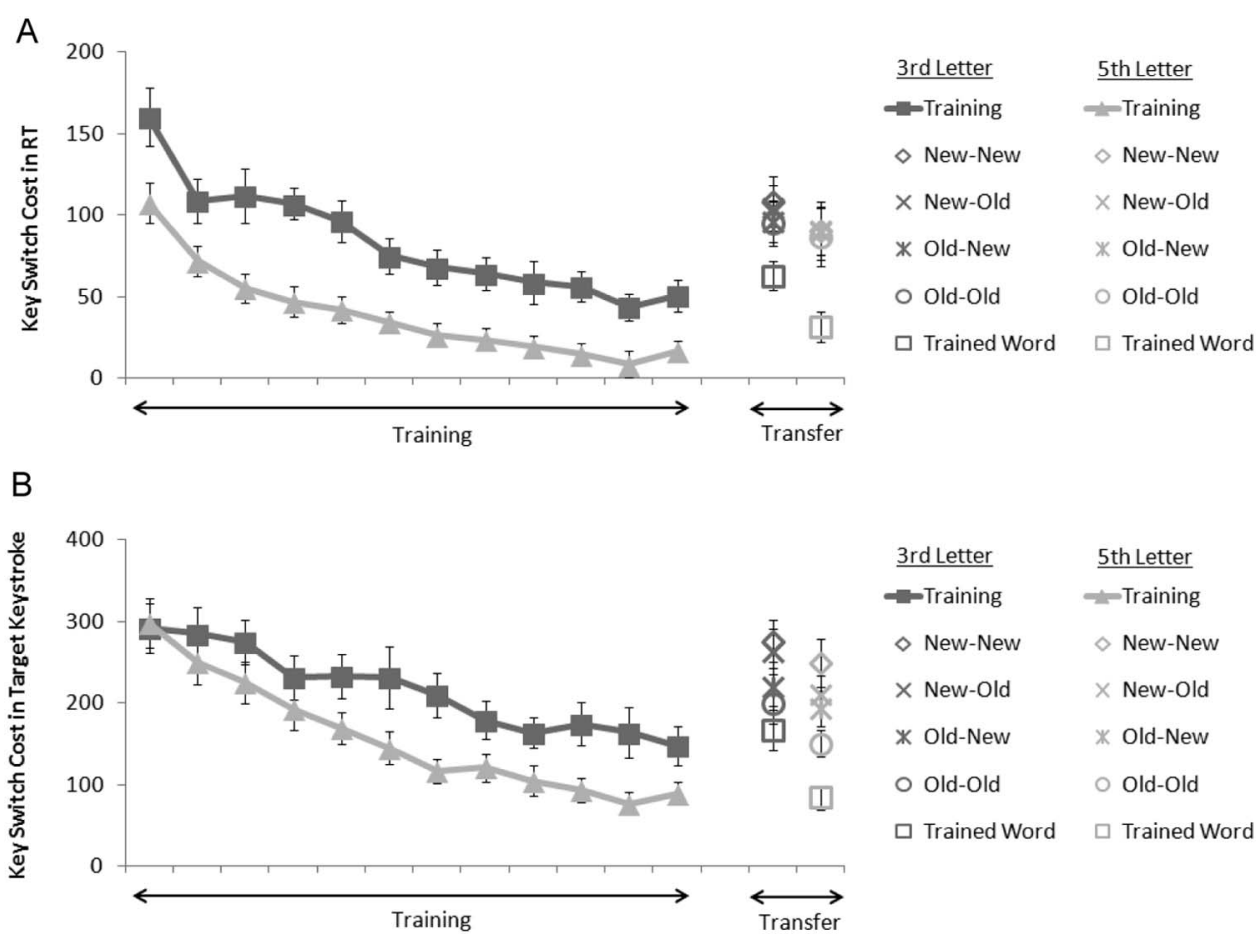

Figure 8. Key switch cost for the 3rd letter trials and for the 5th letter trials in (A) response time (RT) and at (B) interkeystroke interval for the target keystroke as a function of trial block in Experiment 4. Error bars represent the standard error of the means. 
Table 3

Analysis of Variance Table for Switch Cost in Experiment 4

\begin{tabular}{|c|c|c|c|c|c|c|c|c|}
\hline \multirow[b]{2}{*}{ Factor } & \multicolumn{4}{|c|}{ RT } & \multicolumn{4}{|c|}{ Target keystroke } \\
\hline & $d f \mathrm{~s}$ & $F$ & $M S E$ & $\eta_{\mathrm{p}}^{2}$ & $d f \mathrm{~s}$ & $F$ & $M S E$ & $\eta_{\mathrm{p}}^{2}$ \\
\hline Target position $(\mathrm{TP})^{\mathrm{a}}$ & 1,23 & $19.19^{* *}$ & 14,809 & .455 & 1,23 & $16.73^{* *}$ & 29,801 & .421 \\
\hline Trial block (TB) ${ }^{\mathrm{b}}$ & 11,253 & $23.20^{* *}$ & 1,995 & .502 & 11,253 & $36.30^{* * *}$ & 4,758 & .612 \\
\hline $\mathrm{TP} \times \mathrm{TB}$ & 11,253 & 1.04 & 919 & .043 & 11,253 & $2.94^{* * *}$ & 3,197 & .113 \\
\hline $\mathrm{TP}^{\mathrm{a}}$ & 1,23 & 1.42 & 9,933 & .058 & 1,23 & $18.76^{* *}$ & 7,201 & .449 \\
\hline Trial type $(\mathrm{TT})^{\mathrm{c}}$ & 4,92 & $11.01^{* *}$ & 2,050 & .324 & 4,92 & $26.10^{* * *}$ & 5,254 & .532 \\
\hline $\mathrm{TP} \times \mathrm{TT}$ & 4,92 & $<1$ & 2,879 & .017 & 4,92 & 1.14 & 5,618 & .047 \\
\hline Pre-target (pre) ${ }^{\mathrm{d}}$ & 1,23 & $<1$ & 1,206 & .037 & 1,23 & $31.29^{* *}$ & 2,685 & .576 \\
\hline Post-target (post) & 1,23 & $<1$ & 862 & .005 & 1,23 & $6.66^{*}$ & 2,905 & .224 \\
\hline Pre $\times$ Post & 1,23 & $<1$ & 1,233 & $<.001$ & 1,23 & $<1$ & 2,466 & .004 \\
\hline
\end{tabular}

Note. $\mathrm{RT}=$ response time.

${ }^{\mathrm{a}} \mathrm{TP}$ (3rd letter, 5th letter). $\quad{ }^{\mathrm{b}} \mathrm{TB}\left(1-12\right.$ blocks). $\quad{ }^{\mathrm{c}}$ Trial condition (trained, new-new, new-old, old-new, and old-old words). $\quad{ }^{\mathrm{d}}$ Pre-target digraph (new vs. old). ${ }^{\mathrm{e}}$ Post-target digraph (new vs. old).

${ }^{*} p<.05 . \quad{ }^{* * *} p<.001$.

switch costs at the target keystroke (see Table 3). Key switch cost was $262 \mathrm{~ms}$ for new-new words, $237 \mathrm{~ms}$ for new-old words, $206 \mathrm{~ms}$ for old-new words, and $175 \mathrm{~ms}$ for old-old words, which is compared to a 126-ms cost for trained words (see Figure 8). Fisher's LSD for switch costs in IKSI at the target keystroke (=43 ms) indicated that all of the four transfer conditions showed larger switch costs than that for trained words. These results suggest a word-level learning effect.

To follow up this analysis, we submitted key switch costs at target keystrokes for the four transfer conditions (excluding trained words) to a 2 (Pre-Target Digraph: new vs. old) $\times 2$ (Post-Target Digraph: new vs. old) $\mathrm{ANOVA}^{2}$ (see Table 3), which revealed that switch cost depended on both pre- and post-target digraphs. Key switch cost was larger for new pre-target digraphs $(M=250 \mathrm{~ms})$ than for old pretarget digraphs $(M=190 \mathrm{~ms})$, and for new post-target digraphs $(M=$ $234 \mathrm{~ms})$ than for old post-target digraphs $(M=206 \mathrm{~ms})$. The analysis suggests that the pre-target digraph had a larger effect than the post-digraph, but the difference was only marginally significant, $t(23)=1.867, p=.075 .^{3}$

Finally, to examine letter-level learning, we compared key switch cost for new-new trials with switch cost for the first training block in a 2 (Target Position) $\times 2$ (Trial Block) ANOVA, which only showed a significant main effect of Trial Block, $F(1,23)=23.78, M S E=$ $44,224, p<.001, \eta_{\mathrm{p}}^{2}=.508$. Key switch cost was $295 \mathrm{~ms}$ for the first training block and was reduced to $85 \mathrm{~ms}$ for new-new trials, indicating $210 \mathrm{~ms}$ of a letter-level learning effect.

\section{Discussion}

The present experiment showed that key switch cost in RT depended mainly on word-level learning but little on digraph-level learning, because the manipulations of pre- and post-target digraphs did not influence key switch cost. On the other hand, key switch cost IKSI at the target keystroke depended on learning at the word level, letter level, and digraph level, including both pre- and post-target digraphs. Therefore, acquisition of a new letter-key association involves learning at word, letter, and digraph levels. Implications for the models of sequential behavior are discussed below.

\section{General Discussion}

The present study investigated the role of letter-key associations in the control of typing skill by moving one of the 26 letter keys to a novel position on the keyboard (Gordon et al., 1994; Jordan, 1995). Experiment 1 assessed how breaking a pre-existing letter-key association affects skilled typewriting, showing large key switch costs in RT as well as in IKSI at the target keystroke. Thus, altering a key position affects planning of the entire keystroke sequence as well as the execution of the target keystroke. Experiment 2 examined acquisition of new letter-key associations and showed that newly acquired letter-key association affected inner-loop processing, but not outerloop processing. Experiment 3 showed that both word- and letter-level learning contributed to the acquisition of new letter-key associations in the inner loop, whereas only word-level learning took place in the outer loop. Experiment 4 demonstrated the contribution of digraphlevel learning to the acquisition of new letter-key associations in the inner loop, showing that digraphs before and after the target letter both influence the acquisition of new associations.

\section{Hierarchical Control Versus Recurrent Network}

The present experiments have important implications for the mechanisms underlying control of sequential behaviors, distinguishing hierarchical control models (Cooper \& Shallice, 2006; Lashley, 1951; Rumelhart \& Norman, 1982) from recurrent network models (Botvinick \& Plaut, 2004; Elman, 1990; Jordan, 1986), which predict different patterns of the digraph-level learning effects. Hierarchical control models are based on the idea of chunking (see Figure 1A), in which elements in an event sequence are bundled into a single unit (a

\footnotetext{
${ }^{2}$ The same ANOVA was conducted on switch cost in RT and is summarized in Table 3, showing no statistically significant effects of preand post-target digraphs.

3 The pre-target effect is (new-new - old-new $)+$ (new-old - oldold), and the post-target effect is (new-new - new-old) + (old-new old-old). Thus, the difference between the pre-target effect and the posttarget effect is equal to twice the difference between new-old and oldnew.
} 
"parent" unit). Activating the parent unit (e.g., word) activates all the "child" units (e.g., letters) associated with the parent. Altering any of the elements in the parent unit would reduce or eliminate the contribution of the unit, so both the element that precedes and the element that follows the target would affect activation of the target. Therefore, hierarchical control models predict that both pre-target digraph and post-target digraph should affect target keystroke.

Recurrent network models are based on the idea of serial chaining (see Figure 1B) in which the outcome of stimulus processing serves as an input to the next stimulus processing. Thus, producing one outcome unit will automatically activate the next stimulus unit, associating two event units in a sequential manner. Altering a unit that precedes another unit would disable the activation of the following unit, but altering a unit that follows another unit would leave the activation of the preceding unit intact. Therefore, recurrent network models predict that manipulating pre-target digraphs should affect target keystroke, but manipulating post-target digraphs should not.

The effects of pre- and post-target digraphs obtained in Experiment 4 support hierarchical control models. This does not necessarily rule out control based on serial-chain activation, because hierarchical models and recurrent network models are not mutually exclusive. Indeed, Experiment 4 suggests that although this effect did not reach statistical significance, the effect of pre-target digraphs is somewhat larger than the effect of post-target digraphs, which may occur if two mechanisms contribute to the pre-target digraph effect collectively. It is thus possible that both serial chaining and chunking control the execution of pre-target digraphs. Nevertheless, the results do suggest that the serial-chain activation is not sufficient to account for the present data.

\section{The Role of Letter-Key Associations in Skilled Typewriting}

We suggested that three types of associations support skilled typewriting; associations between words and letters, between letters and keys, and between keys and fingers (Yamaguchi \& Logan, 2014). The associations between letters and keys are important for skilled typewriting because they allow typing to proceed without explicit awareness of the locations of keys on the keyboard (Liu et al., 2010; Snyder et al., 2014), letting the inner loop to translate letters to keys directly. If the location of a target key is altered, the inner loop cannot utilize the existing letter-key association, so the outer loop has to implement the new letter-key association using explicit knowledge of the new mapping. Thus, key switch cost reflects an involvement of the outer loop in keystroke execution. Consequently, the reduction in key switch costs in the training phase of the present experiments can be attributed partly to a transition from letter-key translation in the outer loop to letter-key translation in the inner loop.

In Experiment 2, reductions in key switch costs were observed for all target keystrokes throughout training. In the transfer phase, moving the target key back to the original location interfered with the inner loop and not with the outer loop. This suggests that the newly acquired letter-key association was automatically retrieved and competed with the original letter-key association. This is consistent with our suggestion that letter-key associations support skilled typewriting by allowing typists to translate letters to keys without explicit awareness of the corresponding key locations.

Experiments 3 and 4 suggest that letter-key associations play an important role in the development of hierarchical control of skilled typewriting. Key switch cost in RT depended only on word-level learning, but key switch cost in IKSI (at the target keystrokes) depended on learning at word, digraph, and letter levels. These observations are interesting because they imply that although translation from letters to keys depends on one-to-one mapping rules, the mapping rules are not independent. If they were independent, there should be no influence of digraphs or words, but there was, so key switch cost cannot fully be accounted for by letter-level processes. The digraph and word effects suggest that letter-key associations are retrieved as groups or chunks, as typists repeat typing the same sequences of letters. Therefore, the present study supports the idea that the emergence of hierarchical control depends on the acquisition of many kinds of associations: words to letters, letters to keys, and keys to keystrokes (as well as letters to fingers; Beilock \& Holt, 2007; Jordan, 1995; Rieger, 2004). This hypothesis needs to be submitted to further tests in future investigations.

\section{Concluding Remarks}

Researchers have proposed that skilled typewriting is supported by hierarchical control processes (Fendrick, 1937; Lashley, 1951; Logan \& Crump, 2011; Rumelhart \& Norman, 1982; Shaffer, 1975). The results of the present study corroborated this proposal. Switching a key location affected both planning and execution of keystrokes, and new letter-key associations are formed at the letter level (i.e., inner loop) after practice with the new key location. We also found that multiple linguistic units contributed to the acquisition of new letterkey associations (i.e., words, digraphs, and letters). This result is consistent with the hierarchical control model. It would be interesting to see whether the recurrent network model could be revised to account for the pattern of learning effects obtained in the present study.

\section{References}

Abrahamse, E. L., Ruitenberg, M. F., de Kleine, E., \& Verwey, W. B. (2013). Control of automated behavior: Insights from the discrete sequence production task. Frontiers in Human Neuroscience, 7, 82. doi: 10.3389/fnhum.2013.00082

Beilock, S. L., \& Holt, L. E. (2007). Embodied preference judgments: Can likeability be driven by the motor system? Psychological Science, 18 51-57. doi:10.1111/j.1467-9280.2007.01848.x

Botvinick, M., \& Plaut, D. C. (2004). Doing without schema hierarchy: A recurrent connectionist approach to routine sequential action and its pathologies. Psychological Review, 111, 395-429. doi:10.1037/0033295X.111.2.395

Bryan, W. L., \& Harter, S. N. (1899). Studies on the telegraphic language: The acquisition of a hierarchy of habits. Psychological Review, 6 , 345-375. doi:10.1037/h0073117

Clegg, B. A., DiGirolamo, G. J., \& Keele, S. W. (1998). Sequential learning. Trends in Cognitive Sciences, 2, 275-281. doi:10.1016/S13646613(98)01202-9

Cohen, A., Ivry, R. I., \& Keele, S. W. (1990). Attention and structure in sequence learning. Journal of Experimental Psychology: Learning, Memory, and Cognition, 16, 17-30. doi:10.1037/0278-7393.16.1.17

Coltheart, M. (1981). The MRC psycholinguistic database. The Quarterly Journal of Experimental Psychology A: Human Experimental Psychology, 33, 497-505. doi:10.1080/14640748108400805

Cooper, R. P., \& Shallice, T. (2006). Hierarchical schemas and goals in the control of behavior. Psychological Review, 113, 887-916. doi:10.1037/ 0033-295X.113.4.887 
Crump, M. J. C., \& Logan, G. D. (2010a). Episodic contributions to sequential control: Learning from a typist's touch. Journal of Experimental Psychology: Human Perception and Performance, 36, 662-672. doi: $10.1037 / \mathrm{a} 0018390$

Crump, M. J. C., \& Logan, G. D. (2010b). Hierarchical control and skilled typing: Evidence for word-level control over the execution of individual keystrokes. Journal of Experimental Psychology: Learning, Memory, and Cognition, 36, 1369-1380. doi:10.1037/a0020696

Crump, M. J. C., \& Logan, G. D. (2010c). Warning: This keyboard will deconstruct-The role of the keyboard in skilled typewriting. Psychonomic Bulletin \& Review, 17, 394-399. doi:10.3758/PBR.17.3.394

Crump, M. J. C., Vaquero, J. M. M., \& Milliken, B. (2008). Context-specific learning and control: The role of awareness, task-relevance, and relative salience. Consciousness and Cognition, 17, 22-36. doi:10.1016/j.concog.2007.01 .004

Davies, M. (2010). The Corpus of Contemporary American English as the first reliable monitor corpus of English. Literary and Linguistic Computing, 25, 447-464. doi:10.1093/llc/fqq018

Elman, J. L. (1990). Finding structure in time. Cognitive Science, 14, 179-211. doi:10.1207/s15516709 $\operatorname{cog} 1402 \_1$

Fendrich, D. W., Healy, A. F., \& Bourne, L. E., Jr. (1991). Long-term repetition effects for motoric and perceptual procedures. Journal of Experimental Psychology: Learning, Memory, and Cognition, 17, 137-151.

Fendrick, P. (1937). Hierarchical skills in typewriting. Journal of Educational Psychology, 28, 609-620. doi:10.1037/h0054049

Gordon, A. M., Casabona, A., \& Soechting, J. F. (1994). The learning of novel finger movement sequences. Journal of Neurophysiology, 72, $1596-1610$

Grudin, J. T. (1983). Error patterns in novice and skilled transcription typing. In W. E. Cooper (Ed.), Cognitive aspects of skilled typewriting (pp. 121-143). doi:10.1007/978-1-4612-5470-6_6

Healy, A. F., Wohldmann, E. L., \& Bourne, L. E., Jr. (2011). How does practice with a reversed mouse influence subsequent speeded aiming performance? A test of global inhibition. Journal of Cognitive Psychology, 23, 559-573. doi:10.1080/20445911.2011.547467

Jordan, M. I. (1986). Serial order: A parallel distributed processing approach (Technical report). San Diego: University of California, Institute for Cognitive Science.

Jordan, M. I. (1995). The organization of action sequences: Evidence from a relearning task. Journal of Motor Behavior, 27, 179-192. doi:10.1080/ 00222895.1995.9941709

Kozlik, J., \& Neumann, R. (2013). Gaining the upper hand: Comparison of alphabetic and keyboard position as spatial features of letters producing distinct S-R compatibility effects. Acta Psychologica, 144, 51-60. doi: 10.1016/j.actpsy.2013.04.015

Kozlik, J., Neumann, R., \& Kunde, W. (2013). ABC versus QWERTZ: Interference from mismatching sequences of letters in the alphabet and on the PC-keyboard. Journal of Experimental Psychology: Human Perception and Performance, 39, 1085-1099. doi:10.1037/a0030952

Lashley, K. S. (1951). The problem of serial order in behavior. In L. A. Jeffress (Ed.), Cerebral mechanisms in behavior (pp. 112-146). New York, NY: Wiley.

Leonard, J. A., \& Newman, R. C. (1964, August 1). Formation of higher habits. Nature, 203, 550-551. doi:10.1038/203550b0

Liu, X., Crump, M. J. C., \& Logan, G. D. (2010). Do you know where your fingers have been? Explicit knowledge of the spatial layout of the keyboard in skilled typists. Memory \& Cognition, 38, 474-484. doi: 10.3758/MC.38.4.474

Logan, G. D. (2003). Simon-type effects: Chronometric evidence for keypress schemata in typewriting. Journal of Experimental Psychology: Human Perception and Performance, 29, 741-757. doi:10.1037/00961523.29.4.741

Logan, G. D., \& Crump, M. J. C. (2009). The left hand doesn't know what the right hand is doing: The disruptive effects of attention to the hands in skilled typewriting. Psychological Science, 20, 1296-1300. doi: 10.1111/j.1467-9280.2009.02442.x

Logan, G. D., \& Crump, M. J. C. (2011). Hierarchical control of cognitive processes: The case for skilled typewriting. In B. Ross (Ed.), The psychology of learning and motivation (Vol. 54, pp. 1-27). Burlington, MA: Academic Press.

Logan, G. D., Miller, A. E., \& Strayer, D. L. (2011). Electrophysiological evidence for parallel response selection in skilled typists. Psychological Science, 22, 54-56. doi:10.1177/0956797610390382

Logan, G. D., \& Zbrodoff, N. J. (1998). Stroop type interference: Congruity effects in color naming with typewritten responses. Journal of Experimental Psychology: Human Perception and Performance, 24, 978 992. doi:10.1037/0096-1523.24.3.978

Newell, A., \& Rosenbloom, P. (1981). Mechanisms of skill acquisition and the law of practice. In J. R. Anderson (Ed.), Cognitive skills and their acquisition (pp. 1-55). Hillsdale, NJ: Erlbaum.

Rhodes, B. J., Bullock, D., Verwey, W. B., Averbeck, B. B., \& Page, M. P. A. (2004). Learning and production of movement sequences: Behavioral, neurophysiological, and model perspectives. Human Movement Science, 23, 699-746. doi:10.1016/j.humov.2004.10.008

Rieger, M. (2004). Automatic keypress activation in skilled typing. Journal of Experimental Psychology: Human Perception and Performance, 30, 555-565. doi:10.1037/0096-1523.30.3.555

Rosenbaum, D. A., Kenny, S. B., \& Derr, M. A. (1983). Hierarchical control of rapid movement sequences. Journal of Experimental Psychology: Human Perception and Performance, 9, 86-102. doi:10.1037/ 0096-1523.9.1.86

Rumelhart, D. E., \& Norman, D. A. (1982). Simulating a skilled typist: A study of skilled cognitive-motor performance. Cognitive Science, 6, 1-36. doi:10.1207/s15516709 $\operatorname{cog} 0601 \_1$

Saffran, J. R., Newport, E. L., Aslin, R. N., Tunick, R. A., \& Barrueco, S. (1997). Incidental language learning: Listening (and learning) out of the corner of your ear. Psychological Science, 8, 101-105. doi:10.1111/j 1467-9280.1997.tb00690.x

Salthouse, T. A., \& Saults, J. S. (1987). Multiple spans in transcription typing. Journal of Applied Psychology, 72, 187-196. doi:10.1037/00219010.72.2.187

Shaffer, L. H. (1975). Control processes in typing. The Quarterly Journal of Experimental Psychology, 27, 419-432. doi:10.1080/ 14640747508400502

Shaffer, L. H. (1986). Skilled typing performance and keyboard design. Current Psychological Research \& Reviews, 5, 119-129. doi:10.1007/ BF02686608

Shaffer, L. H., \& Hardwick, J. (1968). Typing performance as a function of text. The Quarterly Journal of Experimental Psychology, 20, 360369. doi:10.1080/14640746808400175

Snyder, K. M., Ashitaka, Y., Shimada, H., Ulrich, J. E., \& Logan, G. D. (2014). What skilled typists don't know about the QWERTY keyboard Attention, Perception, \& Psychophysics, 76, 162-171. doi:10.3758/ s13414-013-0548-4

Snyder, K. M., \& Logan, G. D. (2013). Monitoring-induced disruption in skilled typewriting. Journal of Experimental Psychology: Human Perception and Performance, 39, 1409-1420. doi:10.1037/a0031007

Stadler, M. A. (1992). Statistical structure and implicit serial learning. Journal of Experimental Psychology: Learning, Memory, and Cognition, 18, 318-327. doi:10.1037/0278-7393.18.2.318

Van den Bergh, O., Vrana, S., \& Eelen, P. (1990). Letters from the heart: Affective categorization of letter combinations in typists and nontypists. Journal of Experimental Psychology: Learning, Memory, and Cognition, 16, 1153-1161. doi:10.1037/0278-7393.16.6.1153

West, L. J., \& Sabban, Y. (1982). Hierarchy of stroking habits at the typewriter. Journal of Applied Psychology, 67, 370-376. doi:10.1037/ 0021-9010.67.3.370 
Yamaguchi, M., Crump, M. J. C., \& Logan, G. D. (2013). Speedaccuracy tradeoff in skilled typewriting: Decomposing the contributions of hierarchical control loops. Journal of Experimental Psychology: Human Perception and Performance, 39, 678-699. doi: 10.1037/a0030512

Yamaguchi, M., \& Logan, G. D. (2014). Pushing typists back on the learning curve: Revealing chunking in skilled typewriting. Journal of Experimental Psychology: Human Perception and Performance, 40, 592-612. doi:10.1037/a0033809
Yamaguchi, M., Logan, G. D., \& Li, V. (2013). Multiple bottlenecks in hierarchical control of action sequences: What does "response selection" select in skilled typewriting? Journal of Experimental Psychology: Human Perception and Performance, 39, 1059-1084. doi:10.1037/ a0030431

Yamaguchi, M., \& Proctor, R. W. (2009). Transfer of learning in choicereactions: Contributions of specific and general components of manual responses. Acta Psychologica, 130, 1-10. doi:10.1016/j.actpsy.2008.09 .008

\section{Appendix}

\section{Analyses of Response Times and Error Percentages}

Mean response time (RT), target keystroke latency, and percentage of error (PE) trials are summarized in Tables A1, A2, A3, and A4 for Experiments 1-4, respectively. RT and PE were submitted to analyses of variance (ANOVAs; see Table A5). In Experiments 2-4, key switch costs in PE were computed by subtracting PE for the baseline from PE in the training and transfer blocks (see Tables A6 and A7). They were also analyzed by using ANOVAs (see Table A8).

\section{Experiment 1}

RT. We computed RT in terms of Key Switch (switch vs. no switch), Word Length (5 vs. 6 letters), and Target Position (1st vs. 3rd vs. 5th), which is summarized in Table A1. RT was longer when the target key was switched $(M=693 \mathrm{~ms})$ than when it was not $(M=$ $577 \mathrm{~ms}$ ), indicating a key switch cost. Key switch cost was unaffected by word length but depended on target position: The cost was largest when the target was the first letter $(M=178 \mathrm{~ms})$, intermediate when it was the third letter $(M=101 \mathrm{~ms})$, and smallest when it was the fifth letter $(M=69 \mathrm{~ms})$. In addition, RT was generally longer for six-letter words $(M=640 \mathrm{~ms})$ than for five-letter words $(M=630$ $\mathrm{ms})$, which reflects longer keystroke planning for longer words (see Yamaguchi \& Logan, 2014). These results were confirmed

Table A1

Mean Response Time (RT; in ms), Target Keystroke Latency, and Percentage of Error (PE) Trials in Experiment 1

\begin{tabular}{|c|c|c|c|c|c|c|c|}
\hline \multirow[b]{2}{*}{ Word length } & \multirow[b]{2}{*}{ Target position } & \multicolumn{2}{|c|}{ RT } & \multicolumn{2}{|c|}{ Target keystroke } & \multicolumn{2}{|c|}{$\mathrm{PE}$} \\
\hline & & No switch & Switch & No switch & Switch & No switch & Switch \\
\hline \multirow[t]{3}{*}{ 5-letter } & 1st letter & 549 & 721 & 549 & 721 & 7.50 & 9.02 \\
\hline & 3rd letter & 593 & 699 & 140 & 319 & 7.78 & 12.58 \\
\hline & 5 th letter & 574 & 646 & 112 & 223 & 5.83 & 11.37 \\
\hline \multirow{3}{*}{ 6-letter } & 1st letter & 561 & 741 & 561 & 741 & 7.50 & 10.76 \\
\hline & 3rd letter & 600 & 697 & 146 & 341 & 9.44 & 14.89 \\
\hline & 5th letter & 587 & 653 & 119 & 301 & 8.08 & 13.74 \\
\hline
\end{tabular}

Table A2

Mean Response Time (RT; in ms), Target Keystroke Latency, and Percentage of Error (PE) Trials in Experiment 2

\begin{tabular}{|c|c|c|c|c|c|c|c|c|c|}
\hline \multirow[b]{2}{*}{ Block } & \multicolumn{3}{|c|}{ RT } & \multicolumn{3}{|c|}{ Target keystroke } & \multicolumn{3}{|c|}{$\mathrm{PE}$} \\
\hline & 1st letter & 3rd letter & 5th letter & 1st letter & 3rd letter & 5th letter & 1st letter & 3rd letter & 5th letter \\
\hline Baseline & 568 & 611 & 599 & 568 & 148 & 117 & 8.55 & 9.25 & 9.99 \\
\hline Train 1 & 837 & 773 & 721 & 837 & 399 & 361 & 16.40 & 19.54 & 19.54 \\
\hline Train 2 & 817 & 705 & 697 & 817 & 394 & 347 & 14.06 & 16.51 & 20.38 \\
\hline Train 3 & 786 & 682 & 663 & 786 & 380 & 322 & 16.15 & 18.46 & 19.44 \\
\hline Train 4 & 758 & 691 & 656 & 758 & 354 & 278 & 13.63 & 14.01 & 19.38 \\
\hline Train 5 & 742 & 674 & 645 & 742 & 353 & 284 & 14.57 & 14.30 & 18.58 \\
\hline Train 6 & 759 & 694 & 656 & 759 & 332 & 286 & 15.17 & 16.35 & 17.20 \\
\hline Train 7 & 731 & 667 & 638 & 731 & 329 & 253 & 10.24 & 13.73 & 17.57 \\
\hline Train 8 & 731 & 671 & 636 & 731 & 303 & 239 & 12.86 & 16.66 & 15.88 \\
\hline Transfer 1 & 593 & 617 & 606 & 593 & 169 & 142 & 11.81 & 14.78 & 13.37 \\
\hline Transfer 2 & 588 & 610 & 597 & 588 & 160 & 118 & 11.51 & 11.51 & 11.43 \\
\hline
\end{tabular}


Table A3

Mean Response Time (RT; in ms), Target Keystroke Latency, and Percentage of Error (PE) Trials in Experiment 3

\begin{tabular}{|c|c|c|c|c|c|c|c|c|c|}
\hline \multirow[b]{2}{*}{ Block } & \multicolumn{3}{|c|}{$\mathrm{RT}$} & \multicolumn{3}{|c|}{ Target keystroke } & \multicolumn{3}{|c|}{ PE } \\
\hline & 1st letter & 3rd letter & 5th letter & 1st letter & 3rd letter & 5th letter & 1st letter & 3rd letter & 5th letter \\
\hline Baseline & 538 & 571 & 582 & 538 & 130 & 107 & 9.38 & 8.01 & 11.46 \\
\hline Train 1 & 795 & 756 & 700 & 795 & 355 & 353 & 15.50 & 16.50 & 21.63 \\
\hline Train 2 & 745 & 700 & 658 & 745 & 347 & 307 & 12.95 & 17.01 & 17.92 \\
\hline Train 3 & 718 & 691 & 646 & 718 & 348 & 273 & 11.42 & 16.55 & 17.58 \\
\hline Train 4 & 729 & 665 & 643 & 729 & 315 & 253 & 12.58 & 12.63 & 15.81 \\
\hline Train 5 & 696 & 666 & 627 & 696 & 302 & 243 & 10.32 & 10.24 & 14.00 \\
\hline Train 6 & 713 & 653 & 624 & 713 & 283 & 224 & 10.83 & 14.80 & 16.16 \\
\hline Train 7 & 689 & 645 & 620 & 689 & 258 & 211 & 10.62 & 15.56 & 13.05 \\
\hline Train 8 & 676 & 641 & 616 & 676 & 254 & 204 & 10.69 & 14.63 & 14.67 \\
\hline Transfer 1 & 740 & 702 & 694 & 740 & 327 & 268 & 18.01 & 21.00 & 24.88 \\
\hline Transfer 2 & 711 & 688 & 666 & 711 & 314 & 257 & 13.37 & 18.16 & 16.43 \\
\hline
\end{tabular}

statistically by a 2 (Key Switch) $\times 2$ (Word Length) $\times 3$ (Target Position) analysis of variance (ANOVA; see Table A5).

PE. PE was generally larger when the target was at a new location $(M=12.06 \%)$ than when it was at the original position $(M=7.69 \%)$, which represent key switch cost in PE. PE was also larger for six-letter words $(M=10.73 \%)$ than for fiveletter words $(M=9.01 \%)$. Finally, PE depended on target

Table A4

Mean Response Time (RT; in ms), Target Keystroke Latency, and Percentage of Error (PE) Trials in Experiment 4

\begin{tabular}{|c|c|c|c|c|c|c|}
\hline \multirow[b]{2}{*}{ Block } & \multicolumn{2}{|c|}{ RT } & \multicolumn{2}{|c|}{$\begin{array}{c}\text { Target } \\
\text { keystroke }\end{array}$} & \multicolumn{2}{|c|}{ PE } \\
\hline & $\begin{array}{l}3 \mathrm{rd} \\
\text { letter }\end{array}$ & $\begin{array}{l}5 \text { th } \\
\text { letter }\end{array}$ & $\begin{array}{l}\text { 3rd } \\
\text { letter }\end{array}$ & $\begin{array}{l}5 \text { th } \\
\text { letter }\end{array}$ & $\begin{array}{l}3 \mathrm{rd} \\
\text { letter }\end{array}$ & $\begin{array}{c}5 \text { th } \\
\text { letter }\end{array}$ \\
\hline Baseline & 564 & 562 & 126 & 110 & 17.86 & 18.00 \\
\hline Train 1 & 725 & 669 & 418 & 408 & 19.1 & 15.0 \\
\hline Train 2 & 673 & 634 & 410 & 361 & 17.3 & 15.4 \\
\hline Train 3 & 676 & 617 & 400 & 335 & 18.2 & 15.0 \\
\hline Train 4 & 671 & 609 & 357 & 302 & 16.5 & 15.7 \\
\hline Train 5 & 661 & 604 & 359 & 280 & 15.9 & 16.1 \\
\hline Train 6 & 639 & 596 & 357 & 255 & 15.3 & 12.4 \\
\hline Train 7 & 633 & 588 & 336 & 226 & 15.3 & 15.3 \\
\hline Train 8 & 629 & 585 & 305 & 231 & 17.4 & 16.5 \\
\hline Train 9 & 623 & 581 & 289 & 215 & 13.0 & 17.4 \\
\hline Train 10 & 621 & 577 & 300 & 203 & 14.8 & 15.5 \\
\hline Train 11 & 608 & 570 & 290 & 187 & 20.2 & 19.8 \\
\hline Train 12 & 615 & 578 & 273 & 199 & 21.5 & 20.3 \\
\hline New-New & 673 & 652 & 276 & 249 & 26.21 & 26.47 \\
\hline New-Old & 669 & 652 & 263 & 211 & 24.79 & 24.31 \\
\hline Old-New & 660 & 652 & 219 & 193 & 23.21 & 23.76 \\
\hline Old-Old & 660 & 648 & 199 & 151 & 17.14 & 18.69 \\
\hline Trained & 627 & 594 & 167 & 84 & 13.41 & 11.99 \\
\hline
\end{tabular}

position; it was largest when the target was the 3 rd letter $(M=$ $11.17 \%)$, intermediate when it was at the 5th letter $(M=$ $9.75 \%)$, and smallest when it was at the 1 st letter $(M=8.69 \%)$. These observations are supported by a 2 (Key Switch: switch vs. no switch) $\times 2$ (Word Length: 5 vs. 6 letters $) \times 3$ (Target Position: 1st, 3rd, and 5th) ANOVA. Results are summarized in Table A5.

Table A5

Analysis of Variance Table for Response Time (RT) and Percentage of Error (PE) Trials in Experiment 1 as a Function of Key Switch (KS; Switch vs. No Switch), Target Position (TP; 1st, 3rd, 5th), and Word Length (WL; 5 Letter vs. 6 Letter)

\begin{tabular}{|c|c|c|c|c|}
\hline Factor & $d f_{\mathrm{s}}$ & $F$ & $M S E$ & $\eta_{\mathrm{p}}^{2}$ \\
\hline \multicolumn{5}{|c|}{$\mathrm{RT}$} \\
\hline $\mathrm{KS}$ & 1,23 & $155.60^{* *}$ & 6,240 & .871 \\
\hline $\mathrm{TP}$ & 2,46 & $7.21^{*}$ & 4,126 & .239 \\
\hline WL & 1,23 & $7.16^{*}$ & 987 & .237 \\
\hline $\mathrm{KS} \times \mathrm{TP}$ & 2,46 & $33.71^{* *}$ & 2,224 & .594 \\
\hline $\mathrm{KS} \times \mathrm{WL}$ & 1,23 & $<1$ & 772 & .014 \\
\hline $\mathrm{TP} \times \mathrm{WL}$ & 2,46 & 2.7 & 527 & .105 \\
\hline $\mathrm{KS} \times \mathrm{TP} \times \mathrm{WL}$ & 2,46 & $<1$ & 344 & .029 \\
\hline \multicolumn{5}{|c|}{ PE } \\
\hline $\mathrm{KS}$ & 1,23 & $19.11^{* *}$ & 71.97 & .454 \\
\hline TP & 2,46 & $6.36^{*}$ & 23.39 & .216 \\
\hline WL & 1,23 & $5.02^{*}$ & 42.45 & .179 \\
\hline $\mathrm{KS} \times \mathrm{TP}$ & 2,46 & 2.38 & 30.28 & .094 \\
\hline $\mathrm{KS} \times \mathrm{WL}$ & 1,23 & $<1$ & 18.02 & .290 \\
\hline $\mathrm{TP} \times \mathrm{WL}$ & 2,46 & $<1$ & 23.94 & .024 \\
\hline $\mathrm{KS} \times \mathrm{TP} \times \mathrm{WL}$ & 2,46 & $<1$ & 36.75 & .005 \\
\hline
\end{tabular}


Table A6

Key Switch Cost in Percentage of Error Trials in Experiments 2-4

\begin{tabular}{|c|c|c|c|c|c|c|c|c|c|c|c|c|c|c|}
\hline \multirow[b]{2}{*}{ Target position } & \multicolumn{12}{|c|}{ Training } & \multicolumn{2}{|c|}{ Transfer } \\
\hline & 1 & 2 & 3 & 4 & 5 & 6 & 7 & 8 & 9 & 10 & 11 & 12 & 1 & 2 \\
\hline \multicolumn{15}{|c|}{ Experiment 2} \\
\hline 1st letter & 7.85 & 5.51 & 7.59 & 5.08 & 6.02 & 6.62 & 1.69 & 4.31 & & & & & 3.25 & 2.96 \\
\hline 3 rd letter & 10.29 & 7.25 & 9.20 & 4.76 & 5.04 & 7.09 & 4.48 & 7.41 & & & & & 5.52 & 2.25 \\
\hline 5th letter & 9.55 & 10.39 & 9.45 & 9.39 & 8.59 & 7.21 & 7.58 & 5.89 & & & & & 3.38 & 1.45 \\
\hline \multicolumn{15}{|c|}{ Experiment 3} \\
\hline 1st letter & 6.11 & 3.57 & 2.03 & 3.19 & 0.94 & 1.45 & 1.24 & 1.31 & & & & & 8.63 & 3.99 \\
\hline 3rd letter & 8.49 & 9.01 & 8.54 & 4.62 & 2.23 & 6.80 & 7.55 & 6.62 & & & & & 12.99 & 10.15 \\
\hline 5th letter & 10.17 & 6.46 & 6.13 & 4.35 & 2.54 & 4.70 & 1.59 & 3.21 & & & & & 13.42 & 4.97 \\
\hline \multicolumn{15}{|c|}{ Experiment 4} \\
\hline 3rd letter & 11.78 & 10.57 & 11.83 & 9.97 & 10.91 & 9.25 & 8.64 & 8.02 & 7.99 & 10.14 & 5.71 & 7.49 & & \\
\hline 5th letter & 6.18 & 5.59 & 2.59 & 3.01 & 2.60 & 3.25 & 3.67 & -0.05 & 2.94 & 4.10 & 5.01 & 3.12 & & \\
\hline
\end{tabular}

\section{Experiment 2}

Key switch cost in PE. In the training phase, switch cost in PE (see Table A6) decreased over blocks from 9.23\% in the first block to $5.87 \%$ in the last block. A 3 (Target Position: 1st, 3rd, and 5 th) $\times 8$ (Trial Block) ANOVA (see Table A8) only revealed an effect of Trial Block but no significant difference across the three target positions. In the transfer phase, there was key switch cost in the first block of transfer when target was the first letter $(M=$ $3.25 \%), t(23)=2.30, p<.031$, and the third letter $(M=5.52 \%)$, $t(23)=2.24, p<.035$, although it was not significant when target was the fifth letter $(M=3.38 \%), t(23)=1.52$.

\section{Experiment 3}

Key switch cost in PE. In the training phase, switch cost in PE (see Table A6) decreased over training blocks from $8.36 \%$ in the first block to $3.71 \%$ in the last block. A 3 (Target Position: 1st, 3rd, and 5th) $\times 8$ (Trial Block) ANOVA (see Table A7) revealed no significant difference across the three target positions. In the training phase, switch cost in PE increased in the first transfer block $(M=11.68 \%)$

Table A7

Key Switch Cost in Percentage of Error Trials in the Transfer Phase of Experiment 4

\begin{tabular}{lrcccc}
\hline $\begin{array}{c}\text { Target } \\
\text { position }\end{array}$ & $\begin{array}{c}\text { Trained } \\
\text { word }\end{array}$ & New-New & New-Old & Old-New & Old-Old \\
\hline 3rd letter & 6.12 & 18.92 & 17.50 & 15.92 & 9.84 \\
5th letter & -0.41 & 14.06 & 11.90 & 11.35 & 6.28 \\
\hline
\end{tabular}

compared to that in the last training block $(M=3.71 \%)$, reflecting a word-level learning effect (see Table A8). Switch cost in PE was somewhat larger numerically in the first transfer block $(M=11.68 \%)$ than that in the first training block $(M=8.26 \%)$, but not statistically, thereby suggesting little letter-level learning in PE.

\section{Experiment 4}

Key switch cost in PE. In the training phase, switch cost in PE (see Table A6) showed a larger reduction when target was the third letter $(M=9.46 \%)$ than when it was the fifth letter $(M=$ $3.50 \%$ ), which is reflected in the result of a 2 (Target Position: 3rd vs. 5th) $\times 12$ (Trial Block) ANOVA on PE (see Table A8). Although there was a general trend in which switch cost decreased over blocks, it was not statistically significant. In the training phase, switch cost in PE (see Table A7) was smaller for trained words $(M=2.85 \%)$ than the other conditions $(M \mathrm{~s}=16.49 \%$, $14.70 \%, 13.64 \%$, and $8.06 \%$, respectively, for new-new, new-old, old-new, and old-old words), and it was also smaller when target was the fifth letter $(M=8.64 \%)$ than when it was the third letter $(M=13.66 \%)$. Yet, target position did not influence the differences among the transfer conditions, as indicated by a 2 (Target Position: 3rd vs. 5th) $\times 5$ (Trial Type: trained, new-new, newold, old-new, and old-old) ANOVA in PE (see Table A8). A 2 (Pre-Target Digraph) $\times 2$ (Post-Target Digraph) ANOVA on switch cost for the four transfer conditions (excluding trained words; see Table A8) also indicated that switch cost was larger for new pre- and post-target digraphs $(M \mathrm{~s}=15.59 \%$ and $15.06 \%$, respectively) than for old pre- and post-target digraphs $(M \mathrm{~s}=$ $10.85 \%$ vs. $11.38 \%$, respectively). 
Table A8

Analysis of Variance Table for Key Switch Cost in Percentage of Error Trials in Experiments $2-4$

\begin{tabular}{|c|c|c|c|c|}
\hline Factor & $d f \mathrm{~s}$ & $F$ & $M S E$ & $\eta_{\mathrm{p}}^{2}$ \\
\hline \multicolumn{5}{|c|}{ Experiment 2: Training } \\
\hline Target position $(\mathrm{TP})^{\mathrm{a}}$ & 2,46 & $<1$ & 507.41 & .034 \\
\hline Trial block $(\mathrm{TB})^{\mathrm{b}}$ & 7,161 & $2.08^{*}$ & 80.13 & .083 \\
\hline $\mathrm{TP} \times \mathrm{TB}$ & 14,322 & $<1$ & 52.96 & .035 \\
\hline \multicolumn{5}{|c|}{ Experiment 3: Training } \\
\hline $\mathrm{TP}^{\mathrm{a}}$ & 2,46 & 2.36 & 369.43 & .093 \\
\hline $\mathrm{TB}^{\mathrm{b}}$ & 7,161 & $4.24^{* *}$ & 65.54 & .156 \\
\hline $\mathrm{TP} \times \mathrm{TB}$ & 14,322 & 1.03 & 47.98 & .043 \\
\hline \multicolumn{5}{|c|}{ Experiment 3: Word level } \\
\hline $\mathrm{TP}^{\mathrm{a}}$ & 2,46 & 1.91 & 153.9 & .077 \\
\hline $\mathrm{TB}^{\mathrm{c}}$ & 1,23 & $52.53^{* *}$ & 43.53 & .695 \\
\hline $\mathrm{TP} \times \mathrm{TB}$ & 2,46 & $<1$ & 70.09 & .029 \\
\hline \multicolumn{5}{|c|}{ Experiment 3: Letter level } \\
\hline $\mathrm{TP}^{\mathrm{a}}$ & 2,46 & 1.55 & 164.91 & .063 \\
\hline $\mathrm{TB}^{\mathrm{d}}$ & 1,23 & 1.82 & 231.48 & .073 \\
\hline $\mathrm{TP} \times \mathrm{TB}$ & 2,46 & $<1$ & 65.93 & .008 \\
\hline \multicolumn{5}{|c|}{ Experiment 4: Training } \\
\hline $\mathrm{TP}^{\mathrm{e}}$ & 1,23 & $6.26^{*}$ & 789.32 & .214 \\
\hline $\mathrm{TB}^{\mathrm{f}}$ & 11,253 & 1.17 & 73.89 & .048 \\
\hline $\mathrm{TP} \times \mathrm{TB}$ & 11,253 & $<1$ & 61.3 & .041 \\
\hline \multicolumn{5}{|c|}{ Experiment 4: Transfer } \\
\hline $\mathrm{TP}^{\mathrm{e}}$ & 1,23 & $6.74^{*}$ & 224.46 & .227 \\
\hline Trial type $(\mathrm{TT})^{\mathrm{g}}$ & 4,92 & $14.73^{* *}$ & 102.4 & .39 \\
\hline $\mathrm{TP} \times \mathrm{TT}$ & 4,92 & $<1$ & 101.77 & .006 \\
\hline \multicolumn{5}{|c|}{ Experiment 4: Digraph effect } \\
\hline Pre-target $(\text { pre })^{\mathrm{h}}$ & 1,23 & $7.83^{*}$ & 69 & .254 \\
\hline Post-target (post) ${ }^{\mathrm{i}}$ & 1,23 & $4.85^{*}$ & 67.07 & .174 \\
\hline Pre $\times$ Post & 1,23 & 2.23 & 38.46 & .088 \\
\hline
\end{tabular}

Received October 11, 2013

Revision received April 9, 2014

Accepted April 10, 2014 